\title{
Ginsenoside Rg1 ameliorates aging-induced liver fibrosis by inhibiting the NOX4/NLRP3 inflammasome in SAMP8 mice
}

\author{
YAN LI $^{1 *}$, DUODUO ZHANG ${ }^{1 *}$, LAN LI $^{1 *}$, YULI HAN $^{1}$, XIANAN DONG ${ }^{1}$, \\ LIU YANG ${ }^{1}$, XUEWANG LI $^{1}$, WEIZU LI ${ }^{1}$ and WEIPING LI ${ }^{1,2}$ \\ ${ }^{1}$ Key Laboratory of Anti-Inflammatory and Immunopharmacology, Ministry of Education, Department of Pharmacology, \\ Basic Medicine College, Anhui Medical University, Hefei, Anhui 230032; ${ }^{2}$ Department of Pharmacology, \\ Anqing Medical and Pharmaceutical College, Anqing, Anhui 246052, P.R. China
}

Received July 1, 2021; Accepted August 27, 2021

DOI: $10.3892 / \mathrm{mmr} .2021 .12441$

\begin{abstract}
Aging is often accompanied by liver injury and fibrosis, eventually leading to the decline in liver function. However, the mechanism of aging-induced liver injury and fibrosis is still not fully understood, to the best of our knowledge, and there are currently no effective treatment options available for liver aging. Ginsenoside $\operatorname{Rg} 1(\operatorname{Rg} 1)$ has been reported to exert potent anti-aging effects due to its potential antioxidant and anti-inflammatory activity. The present study aimed to investigate the protective effect and underlying mechanism of action of $\mathrm{Rg} 1$ in aging-induced liver injury and fibrosis in senescence-accelerated mouse prone 8 (SAMP8) mice treated for 9 weeks. The histopathological results showed that the arrangement of hepatocytes was disordered, vacuole-like degeneration occurred in the majority of cells, and collagen IV and TGF- $\beta 1$ expression levels, that were detected via immunohistochemistry, were also significantly upregulated in the SAMP8 group. $\mathrm{Rg} 1$ treatment markedly improved aging-induced liver injury and fibrosis, and significantly downregulated the expression levels of collagen IV and TGF- $\beta 1$. In addition, the dihydroethylene staining and western blotting results showed that Rg1 treatment significantly reduced the levels of reactive oxygen species (ROS) and IL- $1 \beta$, and downregulated the expression levels of NADPH oxidase 4 (NOX4), p47phox, p22phox, phosphorylated-NF- $\mathrm{kB}$, caspase-1, apoptosis-associated speck-like protein containing a $\mathrm{C}$-terminal caspase
\end{abstract}

Correspondence to: Professor Weizu Li or Professor Weiping Li, Key Laboratory of Anti-Inflammatory and Immunopharmacology, Ministry of Education, Department of Pharmacology, Basic Medicine College, Anhui Medical University, 81 Meishan Road, Hefei, Anhui 230032, P.R. China

E-mail: liweizu@126.com

E-mail:1wp19@126.com

*Contributed equally

Key words: ginsenoside Rg1, liver aging, NLR family pyrin domain containing 3 inflammasome, NADPH oxidase 4, oxidative stress recruitment domain and the NLR family pyrin domain containing 3 (NLRP3) inflammasome, which were significantly upregulated in the liver tissues of elderly SAMP8 mice. In conclusion, the findings of the present study suggested that Rg1 may attenuate aging-induced liver injury and fibrosis by reducing NOX4-mediated ROS oxidative stress and inhibiting NLRP3 inflammasome activation.

\section{Introduction}

The number of individuals $>65$ years old worldwide is projected to increase from 524 million in 2010 to $\sim 1.5$ billion by 2050 (1). Elderly individuals are particularly susceptible to developing chronic diseases, including hepatic fibrosis (2). Liver fibrosis is a dynamic process associated with the continuous deposition and resorption of the extracellular matrix, mainly fibrillar collagen (3), which is often the first step in architectural distortion and dysfunction that prevents the normal functioning of the liver (4). If untreated, liver fibrosis may lead to advanced liver cirrhosis and hepatoma (4). Accumulating evidence has suggested that susceptibility to liver fibrosis and hepatitis significantly increases with age (5). Thus, it remains of high importance to study liver aging and the associated underlying mechanisms to provide novel strategies to prevent aging-related liver fibrosis.

The pathogenesis of aging is complex. For the past 40 years or so, oxidative stress has been increasingly recognized as a contributing factor in aging-related diseases (6-8). Oxidative stress is induced by an imbalance between the production of reactive oxygen species (ROS) and the scavenging capacity of the antioxidant system $(9,10)$. It has been reported that excessive production of ROS can cause damage to proteins, lipids and DNA, resulting in a variety of disease types, such as Alzheimer's disease, diabetes, heart failure, chronic fatigue syndrome and cancer (11). NADPH oxidase (NOX) is one of the major sources of ROS, and the family of NOX proteins is composed of the membrane subunit (NOX1-5), p22phox and the cytoplasmic subunits of p67phox, p47phox and Rac1 $(12,13)$. It is worth noting that NOX4 is a constitutively active enzyme and has been found to be widely expressed in the liver, particularly within hepatocytes, hepatic stellate cells and fibroblasts (14). Increasing evidence has indicated that 
oxidative stress caused by NOX4-derived ROS may play a key role in liver fibrosis (15).

Chronic inflammation is another important process that occurs during aging as a result of low-grade elevations of circulating inflammatory mediators (16). Inflammation is a common feature of several age-related pathologies, such as frailty and cardiovascular disease (17), which contributes to the progression of tissue dysfunction (18). It has been reported that inflammation also played an important role in age-related liver injury (19). Inflammasomes, which are large cytoplasmic multiprotein complexes, consist of NLR family pyrin domain containing (NLRP), a cytoplasmic pattern recognition receptor of caspase-1 and apoptosis-associated speck-like protein containing a C-terminal caspase recruitment domain (ASC). According to the findings of previous studies, the NLRP3 inflammasome, a type of inflammasome ubiquitously expressed in numerous tissues, including the liver, was discovered to be involved in the evolution of liver fibrosis and the progression of liver injury and age-related liver disease (20-22). When activated by diverse irritants, such as ATP and cholesterol crystals, as well as bacterial, viral and fungal pathogens $(23,24)$, the NLRP3 inflammasome responds to inflammation by promoting the maturation of a series of proinflammatory cytokines, such as IL-1 $\beta$ and IL-18 (25). In addition, it has been reported that excessive ROS accumulation activated the NLRP3 inflammasome in the liver during the process of aging, eventually leading to aging-associated liver disease (26).

The Senescence-accelerated mouse prone 8 (SAMP8) is a model of accelerated aging solely of genetic origin, which has not been subjected to any experimental manipulation (27). Previous studies have reported that SAMP8 mice displayed extensive liver degeneration, including liver steatosis, hepatocyte ballooning characterized by swollen cells, focal necrosis and inflammation, and fibrosis $(28,29)$. Among these observations, liver fibrosis was the most common and significant pathological change (5). Additionally, SAMP8 mice also have abnormal liver function test results, such as significant increases in alanine aminotransferase (ALT) and aspartate aminotransferase (AST) levels (30). However, there are still no effective methods and drugs for delaying liver aging and aging-related liver injury and fibrosis.

Ginseng has been used for $>2,000$ years and demonstrates several beneficial effects, such as improving liver health and delaying aging (31). Ginsenoside Rg1 (Rg1) is one of the active ingredients in ginseng (32). It has been reported that $\operatorname{Rg} 1$ exerted a protective effect on neuronal damage via inhibition of oxidative stress-induced neuronal apoptosis (33). Moreover, Rg1 was found to ameliorate diabetic cardiomyopathy by inhibiting endoplasmic reticulum (ER) stress-induced apoptosis in diabetic rats (34). Our previous studies discovered that $\mathrm{Rg} 1$ could protect against aging-related renal injuries and neuronal senescence by inhibiting NOX4/2 $(35,36)$. However, to the best of our knowledge, it remains unknown whether $\operatorname{Rg} 1$ protects against aging-related liver injury and fibrosis. The present study aimed to investigate whether $\operatorname{Rg} 1$ treatment ameliorates aging-related liver damage and fibrosis by inhibiting NOX4/NLRP3 signaling to reduce oxidative stress and inflammation in the liver during aging.

\section{Materials and methods}

Animals and treatment. In total, 9 male senescence-accelerated resistant mouse 1 (SAMR1) and 45 male SAMP8 mice (both age, 6 months; weight, 30-40 g) were purchased from the Department of Experimental Animal Science, Peking University Medical Science Center (Beijing, China). The mice were maintained in an environmentally controlled room (temperature, $22-25^{\circ} \mathrm{C}$; relative humidity, $50-70 \%$ ) under a 12-h light/dark cycle with unlimited access to food and water. The SAMP8 mice were randomly divided into five groups ( $n=9$ in each group): i) SAMP8 model group; ii) SAMP8 + apocynin $(50 \mathrm{mg} / \mathrm{kg})$ group; iii) SAMP8 + tempol $(50 \mathrm{mg} / \mathrm{kg})$ group; iv) SAMP8 + Rg1 (5 mg/kg) group; v) SAMP8 + Rg1 $(10 \mathrm{mg} / \mathrm{kg})$ group; and vi) SAMR1 mice group, which were used as the control group. The treatments were administered intragastrically $(0.1 \mathrm{ml} / 10 \mathrm{~g}$ body weight), and the mice treated with either apocynin (MilliporeSigma), tempol (MilliporeSigma) or Rg1 (content $>98 \%$; Chengdu Desite Biotechnology Co., Ltd.) once a day for 9 weeks. The SAMP8 and SAMR1 groups were treated with distilled water for 9 weeks. Following 9 weeks of treatment, six mice in each group were sacrificed via cervical dislocation. The livers were harvested and stored in at $-80^{\circ} \mathrm{C}$ for subsequent use in western blotting experiments, or placed in $4 \%$ paraformaldehyde for $24-48 \mathrm{~h}$ at room temperature for histological examination. The experimental procedures were approved by the Animal Ethics Committee of Anhui Medical University (approval no. LLSC20160183; Hefei, China) and performed in accordance with the Guidelines for the Care and Use of Laboratory Animals (37).

Detection of ROS. The levels of ROS production in the liver of the remaining three mice in different groups of mice were detected using dihydroethylene (DHE) staining. Briefly, $100 \mu \mathrm{M}$ DHE $(0.1 \mathrm{ml} / 10 \mathrm{~g}$; Beyotime Institute of Biotechnology) was injected through the tail vein in each group of mice $(n=3)$. After 30 min, the animals were sacrificed by cervical dislocation and the livers were removed and embedded in optical cutting temperature compound (Sakura Finetek USA, Inc.) at $-20^{\circ} \mathrm{C}$ for $2 \mathrm{~h}$. The liver tissues were subsequently cut into $10-\mu \mathrm{m}$ sections using a frozen microtome (Leica CM3050; Leica Microsystems $\mathrm{GmbH}$ ) at $-20^{\circ} \mathrm{C}$. The sections were washed with PBS and incubated with $5 \mathrm{mg} / \mathrm{l}$ Hoechst 33258 solution (Sigma-Aldrich; Merck KGaA) at room temperature for $5 \mathrm{~min}$. Then, the sections were sealed with anti-fluorescence quenching agent (Beyotime Institute of Biotechnology) and visualized using a fluorescence microscope (Olympus IX72; Olympus Corporation; magnification, x400). Image Pro Plus 6.0 software (Media Cybernetics, Inc.) was used to detect the average density of red fluorescence from three randomly selected fields of view in each section to indicate ROS production.

Pathological examination of the liver tissue. The morphological changes in the liver were examined using H\&E, periodic acid-Schiff (PAS) and Masson's trichrome staining techniques. H\&E staining is the most common method for observing pathological changes in tissues (38). Briefly, liver specimens were fixed in 4\% paraformaldehyde for 24-48 h, dehydrated and paraffin embedded, then cut into $5-\mu \mathrm{m}$ thick 
sections. Liver sections $(n=4)$ were deparaffinized in xylene and rehydrated in graded alcohol series (anhydrous ethanol, $85 \%$ ethanol, $75 \%$ ethanol), then stained with hematoxylin for $3 \mathrm{~min}$ and eosin for $30 \mathrm{sec}$. All these steps were carried out at room temperature. The sections were sealed with neutral resin and observed using a light microscope (Olympus IX72; Olympus Corporation; magnification, x200).

PAS staining is often used to detect the accumulation of acidic glycoproteins to evaluate liver injury (39). For PAS staining, the tissue sections $(n=4)$ were deparaffinized and rehydrated, according to the method described for $\mathrm{H} \& \mathrm{E}$ staining. Then, the sections were stained with Schiff solution for 10 min (Beijing Solarbio Science \& Technology Co., Ltd.), followed by hematoxylin for $3 \mathrm{~min}$. All these steps were conducted at room temperature.

Masson's trichrome staining is an important method for assessing collagen deposition in liver tissue (40). For Masson's trichrome staining, the sections $(n=4)$ were deparaffinized and rehydrated, according to the method described for $\mathrm{H} \& \mathrm{E}$ staining. Then, the sections were stained with hematoxylin, differentiated with acid ethanol, stained in Masson's blue solution (Beijing Solarbio Science \& Technology Co., Ltd.), followed by staining with Fuchsin for $8 \mathrm{~min}$. The cells were then washed with phosphomolybdic acid for $2 \mathrm{~min}$ and stained with aniline blue for $5 \mathrm{~min}$. All these steps were performed at room temperature. PAS- and Masson's trichrome-stained cells were visualized using a light microscope (Olympus IX71; magnification, $x 400$ ). The positive areas of PAS staining appeared purple and the Masson's trichrome stained collagen blue. The results of the PAS and Masson's trichrome staining in the liver were analyzed in three randomly selected fields of view in each section using Image-Pro Plus software (Media Cybernetics, Inc.). The average densities of PAS and Masson's positive areas were calculated to assess the degree of liver fibrosis.

Immunohistochemistry staining. The paraffin-embedded sections $(n=4)$ were deparaffinized and rehydrated, according to the method described for H\&E staining. Then, the sections were incubated with $3 \% \mathrm{H}_{2} \mathrm{O}_{2}$ for $10 \mathrm{~min}$ at $37^{\circ} \mathrm{C}$ to block the endogenous peroxidase activity prior to being immersed in boiling sodium citrate buffer for $7 \mathrm{~min}$ in a microwave oven for antigen retrieval. The sections were subsequently incubated with $10 \%$ goat serum (cat. no. C0265; Beyotime Institute of Biotechnology) at $37^{\circ} \mathrm{C}$ for 30 min to block non-specific binding. The sections were then incubated with the following primary antibodies at $4^{\circ} \mathrm{C}$ overnight: Rabbit polyclonal anti-collagen IV (1:100; Bioworld Biotechnology, Inc.; cat. no. BS1072), rabbit polyclonal anti-NLRP3 (1:100; Bioworld Biotechnology, Inc.; cat. no. BS90949) and rabbit polyclonal anti-TGF- $\beta 1$ (1:100; Abcam; cat. no. ab92486). Following the primary antibody incubation, the sections were reheated to $37^{\circ} \mathrm{C}$ for $30 \mathrm{~min}$ and washed three times with PBS. Then, the sections were incubated with a polymer-coupled sheep anti-rabbit IgG peroxidase-conjugated secondary antibody (1:500; Affinity Biosciences; cat. no. S0001) at $37^{\circ} \mathrm{C}$ for $1 \mathrm{~h}$, then washed three time with PBS. Cells were subsequently incubated with DAB to produce brown staining for $30 \mathrm{sec}$, then stained with hematoxylin for $3 \mathrm{~min}$ both at room temperature, and sealed with neutral resin. Stained cells were visualized under a microscope (Olympus IX71; magnification, x400). Image-Pro Plus software was used to analyze the expression levels of collagen IV, TGF- $\beta 1$ and NLRP3 in three randomly fields of view from each section of liver tissue.

Western blotting. Total protein was extracted from liver tissues $(n=3)$ using RIPA lysis buffer (cat. no. P0013B; Beyotime Institute of Biotechnology) and an automatic sample rapid grinding machine (Jinxing Industrial Development Co., Ltd.) at $65 \mathrm{~Hz}$ for $60 \mathrm{sec}$ at $4^{\circ} \mathrm{C}$. Total protein was quantified using a BCA protein assay kit and the proteins $(20 \mu \mathrm{g})$ were separated via $8-15 \%$ SDS/PAGE. The separated proteins were subsequently transferred onto PVDF membranes (MilliporeSigma) and blocked with 5\% skimmed milk in TBS-0.05\% Tween-20 (TBST) buffer for $1 \mathrm{~h}$ at room temperature. The membranes were then incubated with the following primary antibodies overnight at $4^{\circ} \mathrm{C}$ : Anti-NLRP3 (1:1,000; Bioworld Biotechnology, Inc.; cat. no. BS90949), anti-ASC (1:1,000; BIOSS; cat. no. bs-67412-R), anti-caspase-1 (1:1,000; Abcam; cat. no. ab1872), anti-IL-1 (1:500; Abcam; cat. no. ab9722), anti-NOX4 (1:1,000; Bioworld Biotechnology, Inc.; cat. no. BS60435), anti-p47phox (1:1,000; Bioworld Biotechnology, Inc.; cat. no. BS4852), anti-p22phox (1:1,000; Bioworld Biotechnology, Inc.; cat. no. BS60290), anti-NF-кB p65 (1:1,000; Wuhan Servicebio Technology Co., Ltd.; cat. no. GB11142), anti-phosphorylated (p)-NF-кB p65 (1:1,000; WuhanServicebio Technology Co.,Ltd.; cat.no.GB11142-1) and anti-GAPDH (1:5,000; Affinity Biosciences; cat. no. AF7021). Following the primary antibody incubation, the membranes were washed with TBST three times (10 min each time) and incubated with HRP-conjugated goat anti-rabbit $\operatorname{IgG}(1: 10,000$; Affinity Biosciences; cat. no. S0001) and goat anti-mouse IgG (1:10,000 Affinity Biosciences; cat. no. S0002) secondary antibodies for $1 \mathrm{~h}$ at room temperature. Protein bands were visualized using an ECL kit (Bio-Rad Laboratories, Inc.) and a Bioshine Chemi Imaging System (Q4600 Mini; Shanghai Bioshine Technology). The optical density of each band was semi-quantified using ImageJ 1.53a software (National Institutes of Health) and normalized to GAPDH expression.

Statistical analysis. All data are presented as the mean \pm SD of $\geq 3$ independent experiments. GraphPad Prism 8.0 software (GraphPad Software, Inc.) was used to perform the statistical analyses. One-way ANOVA followed by a Tukey's post hoc test was performed to compare differences among groups. $\mathrm{P}<0.05$ was considered to indicate a statistically significant difference.

\section{Results}

Rg1 treatment ameliorates liver histopathological changes in the liver of SAMP8 mice. The results of the H\&E staining revealed that in the SAMR1 control group, the boundaries of cytoplasm and nuclei of the hepatocytes were clear. The hepatocytes were arranged in cords from the central vein to the surrounding area, and fat droplet vacuoles were occasionally observed. Compared with the SAMR1 group, the cells of the SAMP8 group were not clearly defined, the nuclei were absent or deeply stained, and were squeezed to one side (black arrows). The arrangement of hepatocytes was abnormal and disordered and most of the cells showed vacuole-like 


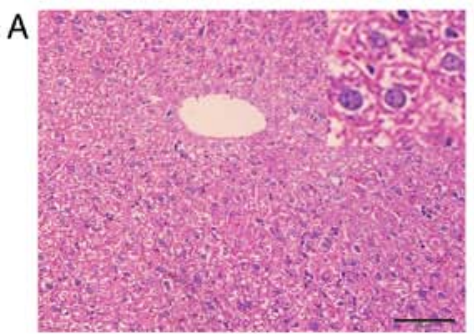

SAMR1

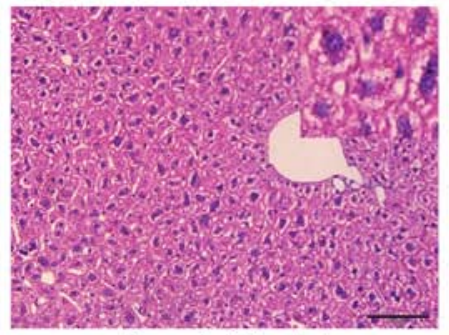

Apocynin $(50 \mathrm{mg} / \mathrm{kg})$

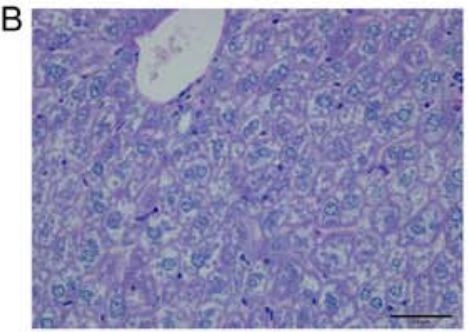

SAMR1

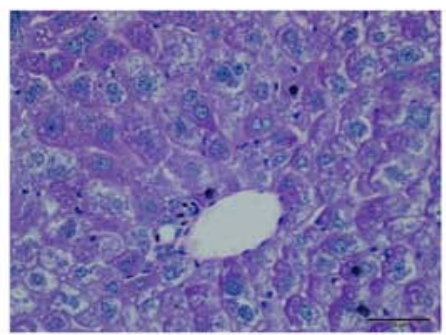

Apocynin $(50 \mathrm{mg} / \mathrm{kg}$ )

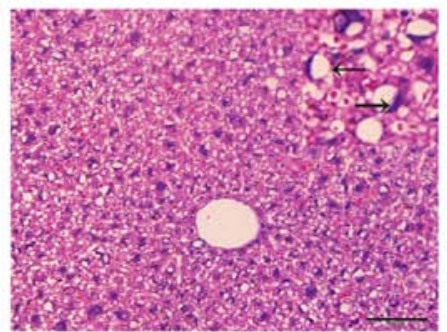

SAMP8

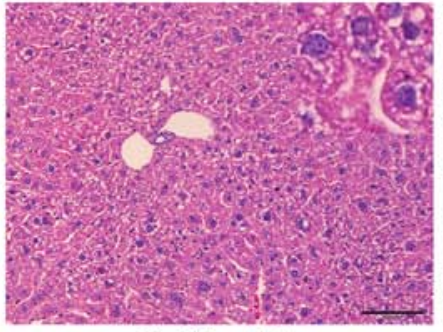

$\mathrm{Rg} 1$ (5 mg/kg)

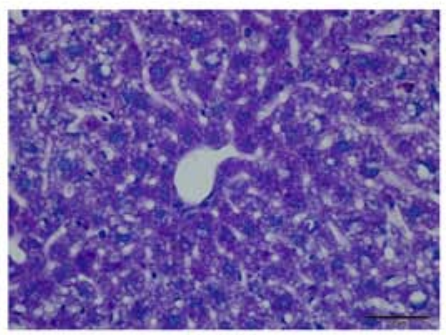

SAMP8

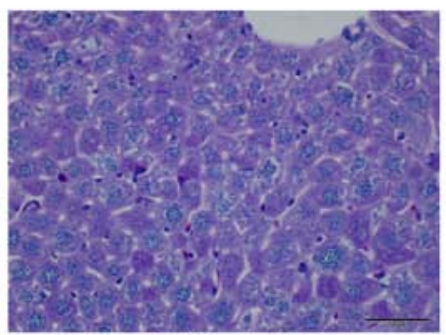

$\mathrm{Rg} 1$ (5 mg/kg)

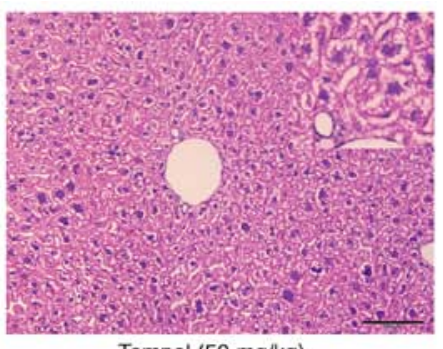

Tempol (50 mg/kg)

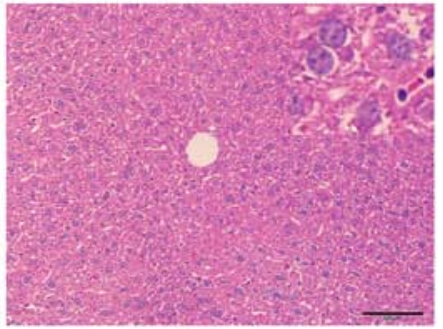

$\mathrm{Rg} 1(10 \mathrm{mg} / \mathrm{kg})$

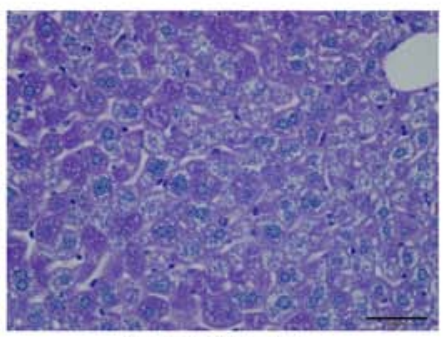

Tempol (50 mg/kg)

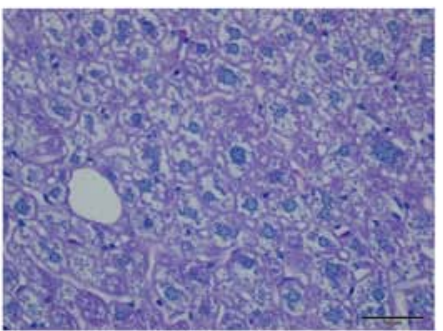

$\mathrm{Rg} 1(10 \mathrm{mg} / \mathrm{kg})$

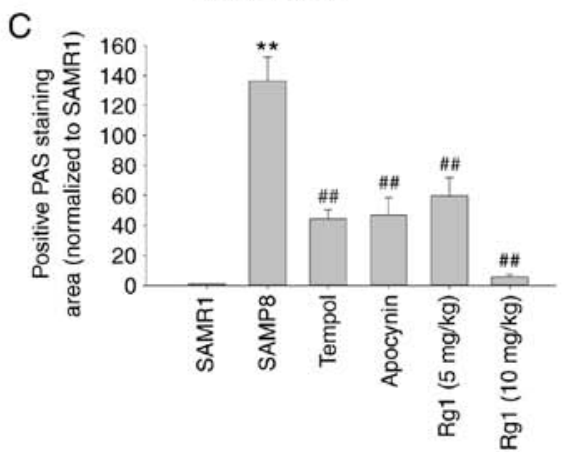

Figure 1.Effects of Rg1 treatment on histopathological changes in the liver in SAMP8 mice.(A) H\&E staining of the liver (Scale bar, 100 $\mu \mathrm{m}$; Magnification, $\mathrm{x} 200$ ). The black arrows indicate that the cells of the SAMP8 group were not clearly defined, the nuclei were absent or deeply stained, and were squeezed to one side. (B) PAS staining of the liver (Scale bar, $50 \mu \mathrm{m}$; Magnification, x400). (C) Positive PAS staining area (normalized to SAMR1 group). Data are presented as the mean $\pm \mathrm{SD} ; \mathrm{n}=4$. ${ }^{* *} \mathrm{P}<0.01$ vs. SAMR1; ${ }^{\# /} \mathrm{P}<0.01$ vs. SAMP8. SAMP8, senescence-accelerated mouse prone 8; SAMR1, senescence-accelerated resistant mouse 1; PAS, periodic acid-Schiff; Rg1, ginsenoside Rg1.

degeneration in the SAMP8 group. However, the tempol $(50 \mathrm{mg} / \mathrm{kg})$, apocynin $(50 \mathrm{mg} / \mathrm{kg})$ and $\mathrm{Rg} 1(5$ and $10 \mathrm{mg} / \mathrm{kg})$ treatment groups showed a marked improvement in liver histopathology compared with the SAMP8 group (Fig. 1A). The PAS staining results also indicated that the hepatocytes were lightly stained, with a uniform distribution of positive areas within the cells in the SAMR1 group. Compared with the SAMR1 group, the accumulation of positive purple staining in hepatocytes was significantly increased in the SAMP8 group, suggesting the presence of significant hepatocyte injury in elderly mice (Fig. 1B and C). Compared with the SAMP8 group, the accumulation of positive staining was significantly 


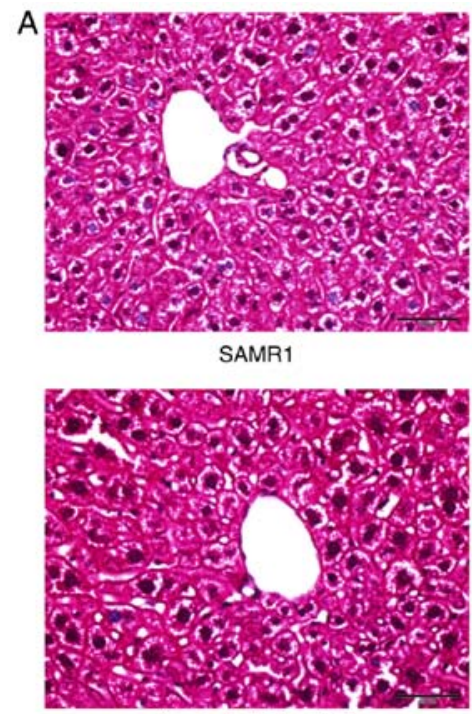

Apocynin $(50 \mathrm{mg} / \mathrm{kg})$

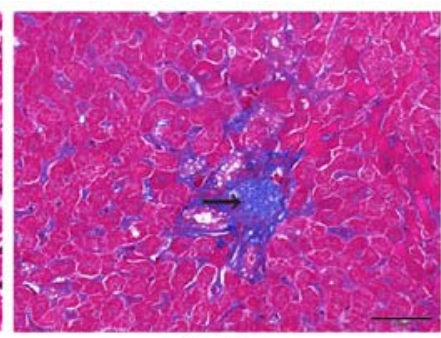

SAMP8

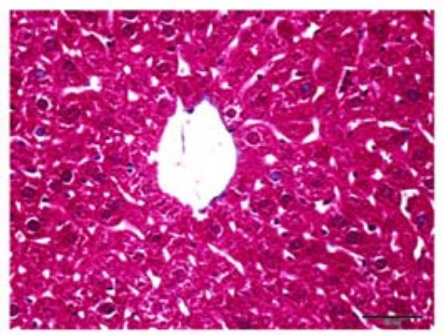

$\mathrm{Rg} 1$ (5 mg/kg)
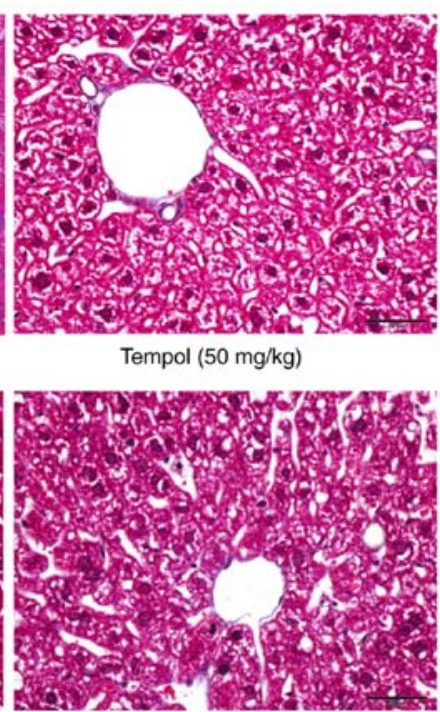

$\operatorname{Rg} 1(10 \mathrm{mg} / \mathrm{kg})$

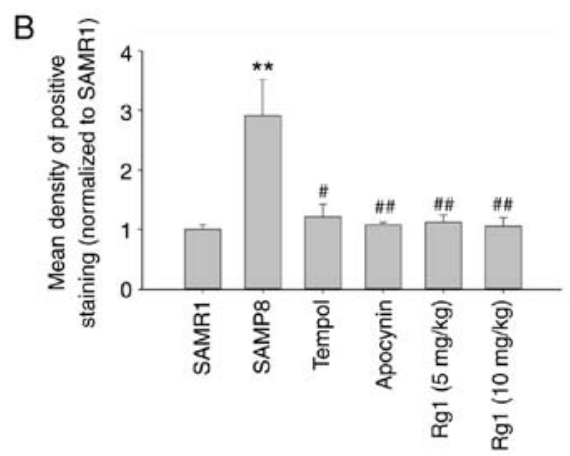

Figure 2. Effects of $\mathrm{Rg} 1$ treatment on liver fibrosis in SAMP8 mice. (A) Masson's trichrome staining in the liver (Scale bar, $50 \mu$ m; magnification, $\mathrm{x} 400$ ). The arrows indicate collagen deposition. (B) Mean density of the positive area of staining in the liver (Masson's trichrome staining). Data are presented as the mean $\pm \mathrm{SD} ; \mathrm{n}=4$. ${ }^{* *} \mathrm{P}<0.01$ vs. SAMR1; ${ }^{\text {}} \mathrm{P}<0.05$, ${ }^{\# \#} \mathrm{P}<0.01$ vs. SAMP8. Rg1, ginsenoside Rg1; SAMP8, senescence-accelerated mouse prone 8; SAMR1, senescence-accelerated resistant mouse 1 .

reduced in the tempol, apocynin and $\mathrm{Rg} 1(5$ and $10 \mathrm{mg} / \mathrm{kg})$ treatment groups (Fig. $1 \mathrm{~B}$ and $\mathrm{C}$ ). These results suggested that Rg1 may significantly ameliorate aging-induced liver injury in mice.

Rgl treatment alleviates liver fibrosis in SAMP8 mice. To explore whether Rg1 alleviates aging-related liver fibrosis, collagen deposition was measured in liver tissues by using Masson's staining. The results showed that the blue positive areas were significantly increased in the liver tissues of the SAMP8 group compared with the SAMR1 group (Fig. 2A and B). However, compared with the SAMP8 model group, the levels of collagen deposition were significantly reduced in the tempol, apocynin and $\mathrm{Rg} 1$ (5 and $10 \mathrm{mg} / \mathrm{kg}$ ) treatment groups (Fig. 2A and B). In addition, the expression levels of collagen IV and TGF- $\beta 1$ were measured in liver tissues by using immunohistochemical staining. The results of the collagen IV staining revealed that collagen IV was expressed at low levels in the liver tissues in the SAMR1 group (Fig. 3A and C). However, compared with the SAMR1 group, the expression levels of collagen IV were significantly upregulated in the SAMP8 group (Fig. 3A and C). Conversely, compared with the SAMP8 group, treatment with tempol, apocynin and $\operatorname{Rg} 1$ (5 and $10 \mathrm{mg} / \mathrm{kg}$ ) significantly decreased collagen IV deposition, especially in the $\mathrm{Rg} 1(10 \mathrm{mg} / \mathrm{kg})$ group (Fig. 3A and C). Furthermore, similar to collagen IV, the expression of TGF- $\beta 1$ was also significantly increased in the SAMP8 group compared with the SAMR1 group, and was significantly decreased following treatment with tempol, apocynin and Rg1 (5 and $10 \mathrm{mg} / \mathrm{kg}$ ), especially in the $\mathrm{Rg} 1$ $(10 \mathrm{mg} / \mathrm{kg}$ ) group (Fig. 3B and D). These results suggested that aging may cause liver tissue fibrosis, and tempol, apocynin and Rg1 treatment may significantly improve liver tissue fibrosis during aging.

Rgl treatment reduces ROS production and NOX4 expression in the liver of SAMP8 mice. ROS is an important factor in the development of hepatic fibrosis (41). In the present study, a ROS probe, DHE, was used to detect the level of ROS production in liver tissues. The results showed that there were low levels of ROS production in the liver tissues of the SAMR1 group. However, compared with the SAMR1 group, the levels of ROS production were significantly increased in the SAMP8 group (Fig. 4A and B), while compared with the SAMP8 group, tempol, apocynin and Rg1 (5 and $10 \mathrm{mg} / \mathrm{kg}$ ) treatment significantly reduced the levels of ROS production in the liver tissues (Fig. 4A and B). To confirm the effect of NOX4 on ROS accumulation during aging, the expression levels of NOX4-related proteins were analyzed. The results demonstrated that, compared with the SAMR1 group, the expression 


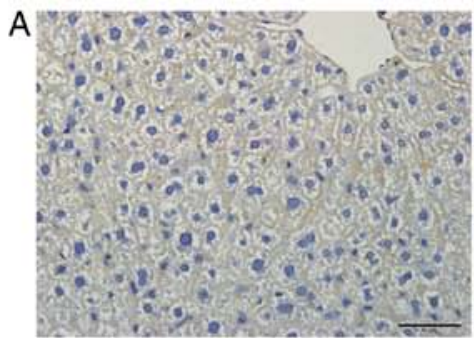

SAMR1

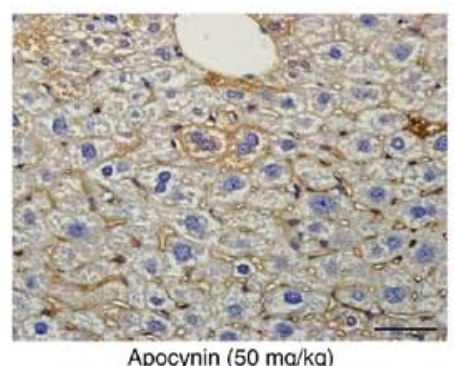

Apocynin (50 mg/kg)

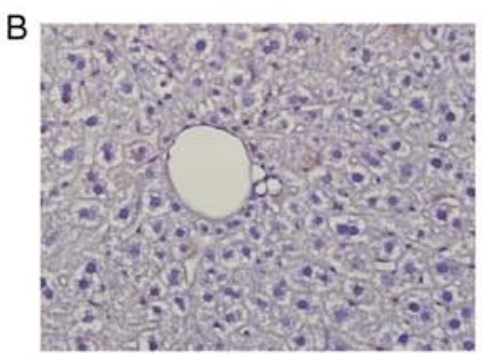

SAMR1

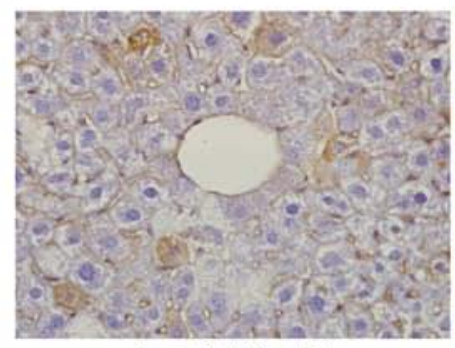

Apocynin $(50 \mathrm{mg} / \mathrm{kg})$

C

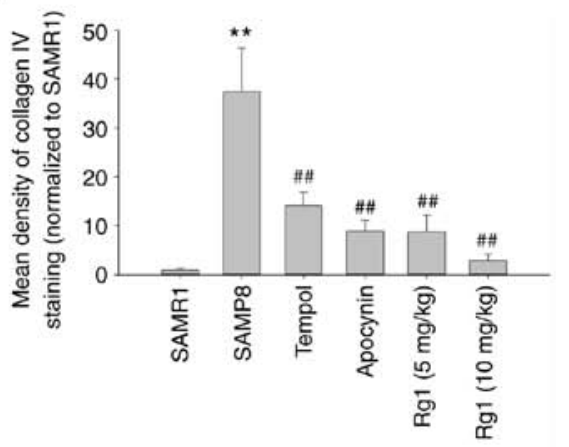

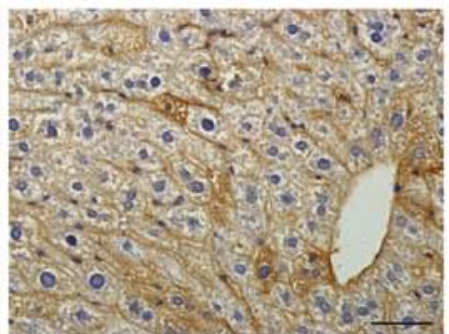

SAMP8

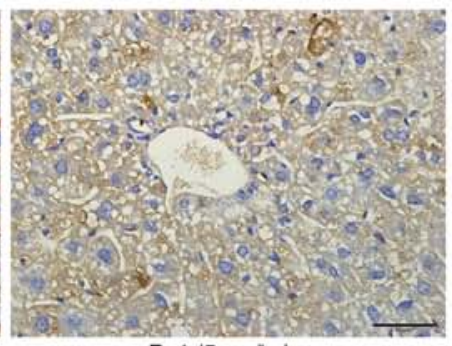

$\mathrm{Rg} 1$ (5 mg/kg)

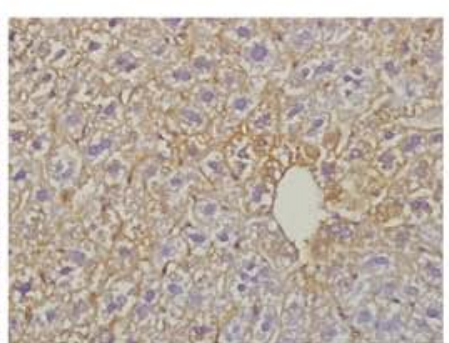

SAMP8

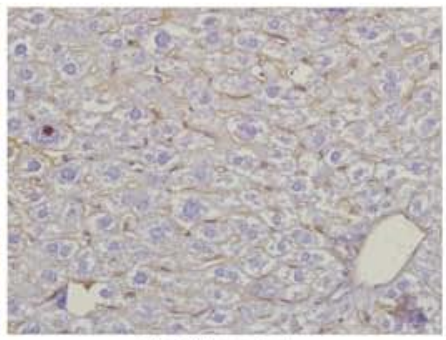

$R g 1(5 \mathrm{mg} / \mathrm{kg})$
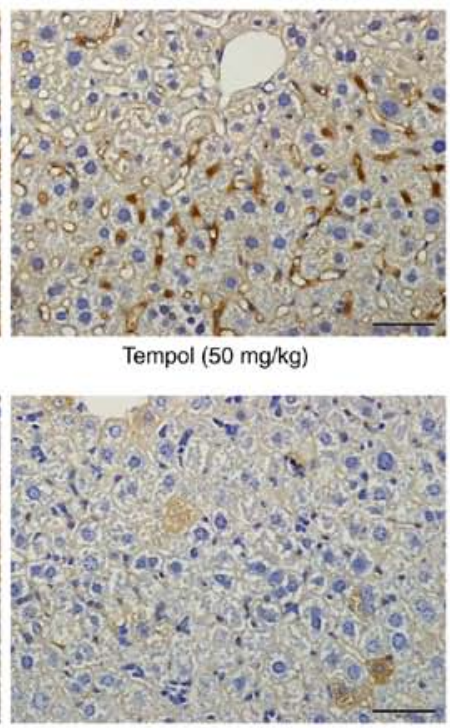

$\mathrm{Rg} 1$ (10 mg/kg)

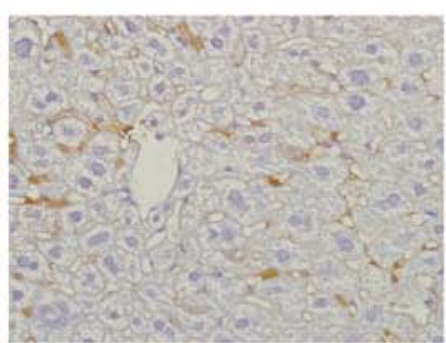

Tempol (50 mg/kg)

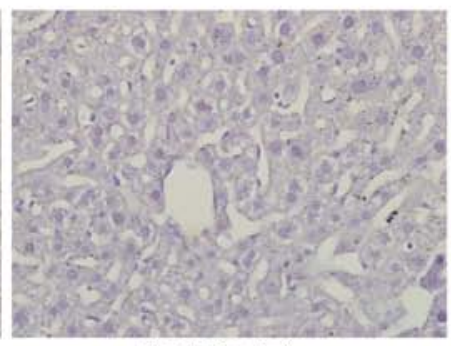

$\mathrm{Rg} 1(10 \mathrm{mg} / \mathrm{kg})$

D

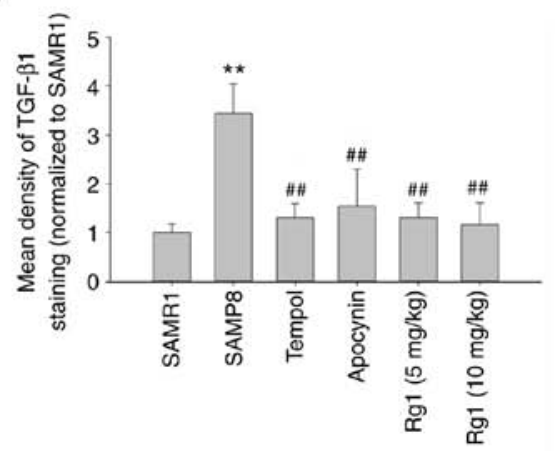

Figure 3. Effects of Rg1 treatment on the expression levels of collagen IV and TGF- $\beta 1$ in the liver of SAMP8 mice. (A) Expression of collagen IV in the liver (Scale bar, $50 \mu \mathrm{m}$; Magnification, x400). (B) Expression of TGF- $\beta 1$ in the liver (Scale bar, $50 \mu \mathrm{m}$; Magnification, $\mathrm{x} 400$ ). (C) Mean density of positive (C) collagen IV and (D) TGF- $\beta 1$ staining area in the liver. Data are presented as the mean \pm SD; $n=4$. ${ }^{* *} \mathrm{P}<0.01$ vs. SAMR1; ${ }^{\# \#} \mathrm{P}<0.01$ vs. SAMP8. Rg1, ginsenoside Rg1; SAMP8, senescence-accelerated mouse prone 8; SAMR1, senescence-accelerated resistant mouse 1.

levels of NOX4, p22phox and p47phox in the liver tissues were significantly upregulated in the SAMP8 group (Fig. 5A-D). However, compared with the SAMP8 group, tempol, apocynin and Rg1 (5 and $10 \mathrm{mg} / \mathrm{kg}$ ) treatment significantly downregulated the expression levels of NOX4, p22phox and p47phox in liver tissues during aging (Fig. 5A-D). These data suggested that Rg1 treatment may ameliorate ROS-induced oxidative stress injury in liver tissues by inhibiting NOX4 during aging in mice. 

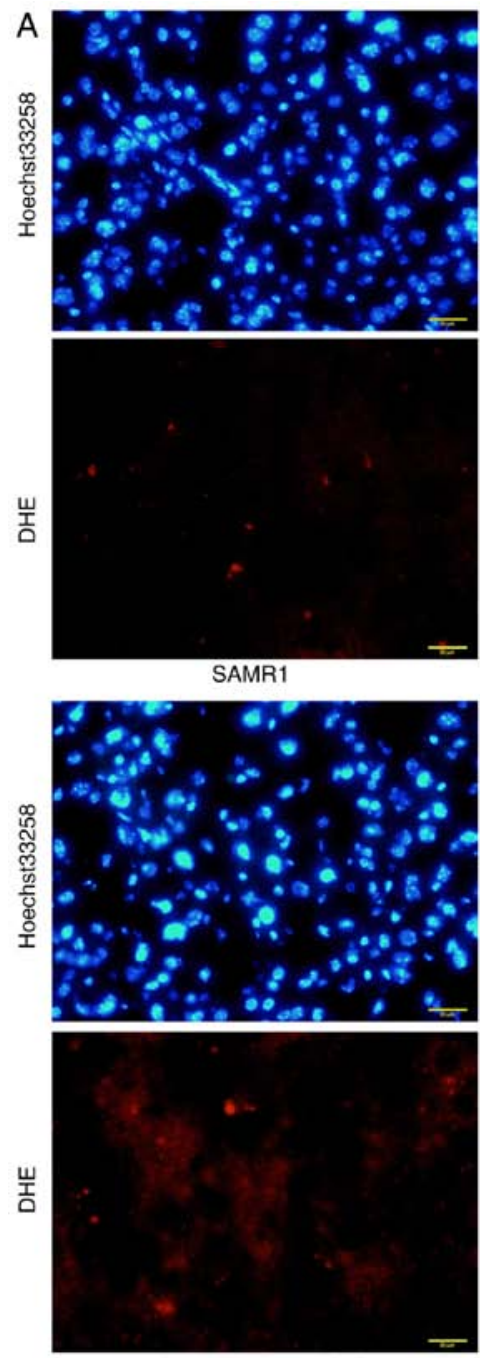

Apocynin $(50 \mathrm{mg} / \mathrm{kg})$

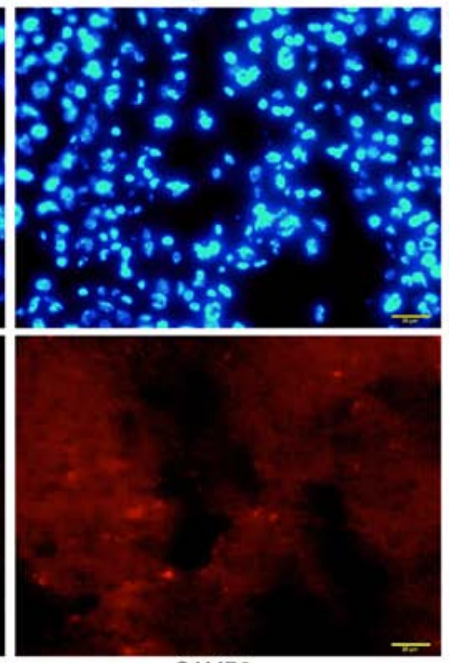

SAMP8
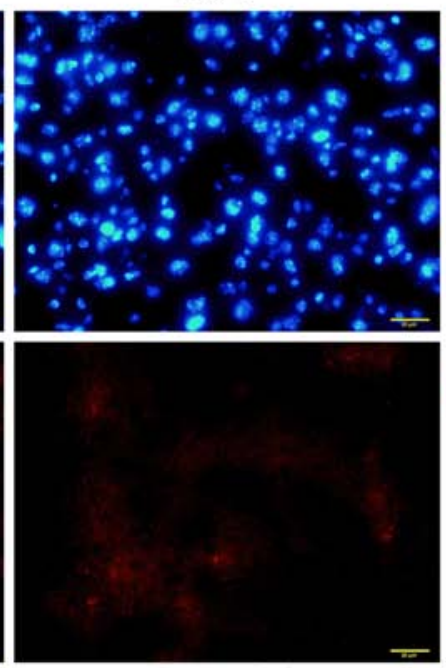

$\mathrm{Rg} 1(5 \mathrm{mg} / \mathrm{kg})$

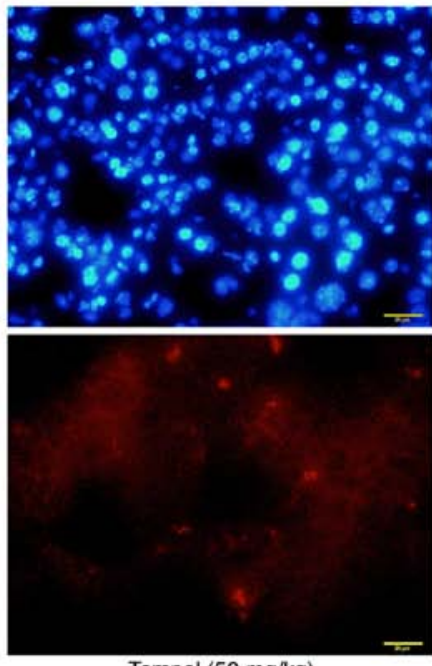

Tempol $(50 \mathrm{mg} / \mathrm{kg})$
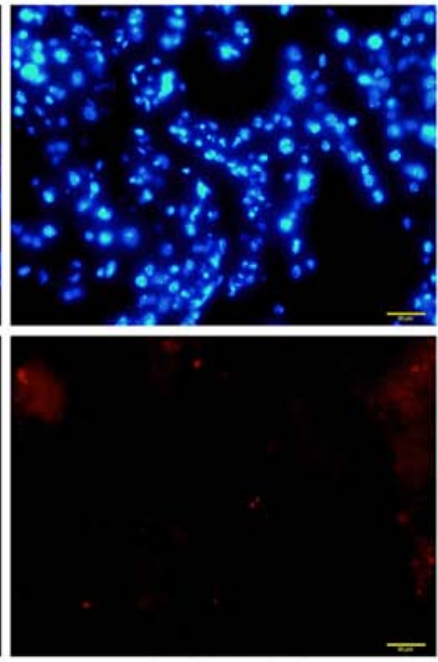

$\operatorname{Rg} 1(10 \mathrm{mg} / \mathrm{kg})$

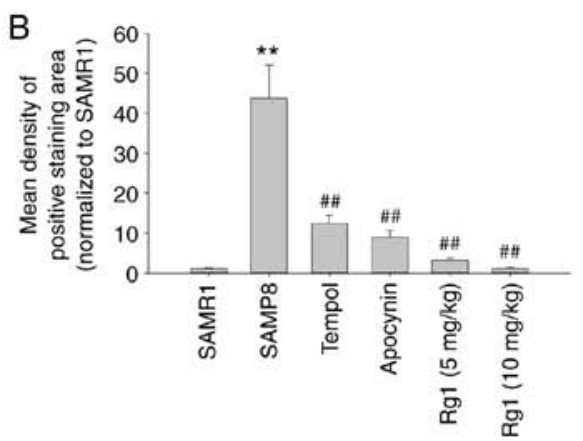

Figure 4. Effect of Rg1 treatment on ROS production in the liver of SAMP8 mice. (A) Accumulation of ROS production in the liver was measured via DHE fluorescence and Hoechst 33258 staining (Scale bar, $20 \mu \mathrm{m}$; Magnification, x400). (B) Mean density of ROS production (red fluorescence) in the liver. Data are presented as the mean $\pm \mathrm{SD} ; \mathrm{n}=3$. ${ }^{* *} \mathrm{P}<0.01$ vs. SAMR1; ${ }^{\# \prime} \mathrm{P}<0.01$ vs. SAMP8. Rg1, ginsenoside Rg1; SAMP8, senescence-accelerated mouse prone 8; SAMR1, senescence-accelerated resistant mouse 1; DHE, dihydroethylene.

Rg1 treatment downregulates the expression levels of NLRP3, $A S C$, caspase-1 and IL-1 $\beta$ in the liver of SAMP8 mice. It has been reported that activation of the NLRP3 inflammasome plays an important role in senescence-related renal fibrosis (42). Therefore, the present study further investigated the expression levels of NLRP3-related proteins to confirm whether the NLRP3 inflammasome is involved in age-related liver fibrosis. The results showed that the expression levels of NLRP3, ASC, caspase- 1 and IL- $1 \beta$ in liver tissues were significantly upregulated in the SAMP8 group compared with the SAMR1 group (Fig. 6A-E). Compared with the SAMP8 group, the tempol, apocynin and $\mathrm{Rg} 1$ (5 and $10 \mathrm{mg} / \mathrm{kg}$ ) treatment groups had significantly downregulated expression levels of NLRP3, ASC, caspase- 1 and IL- $1 \beta$ in the liver tissues of SAMP8 mice (Fig. 6A-E). Immunohistochemical staining was performed to measure the expression levels of NLRP3 in liver tissues. The results were consistent with the expression of NLRP3 measured using western blotting. The expression of NLRP3 was significantly upregulated in the liver of the SAMP8 group compared with the SAMR1 group (Fig. 7A and B), and tempol, apocynin 

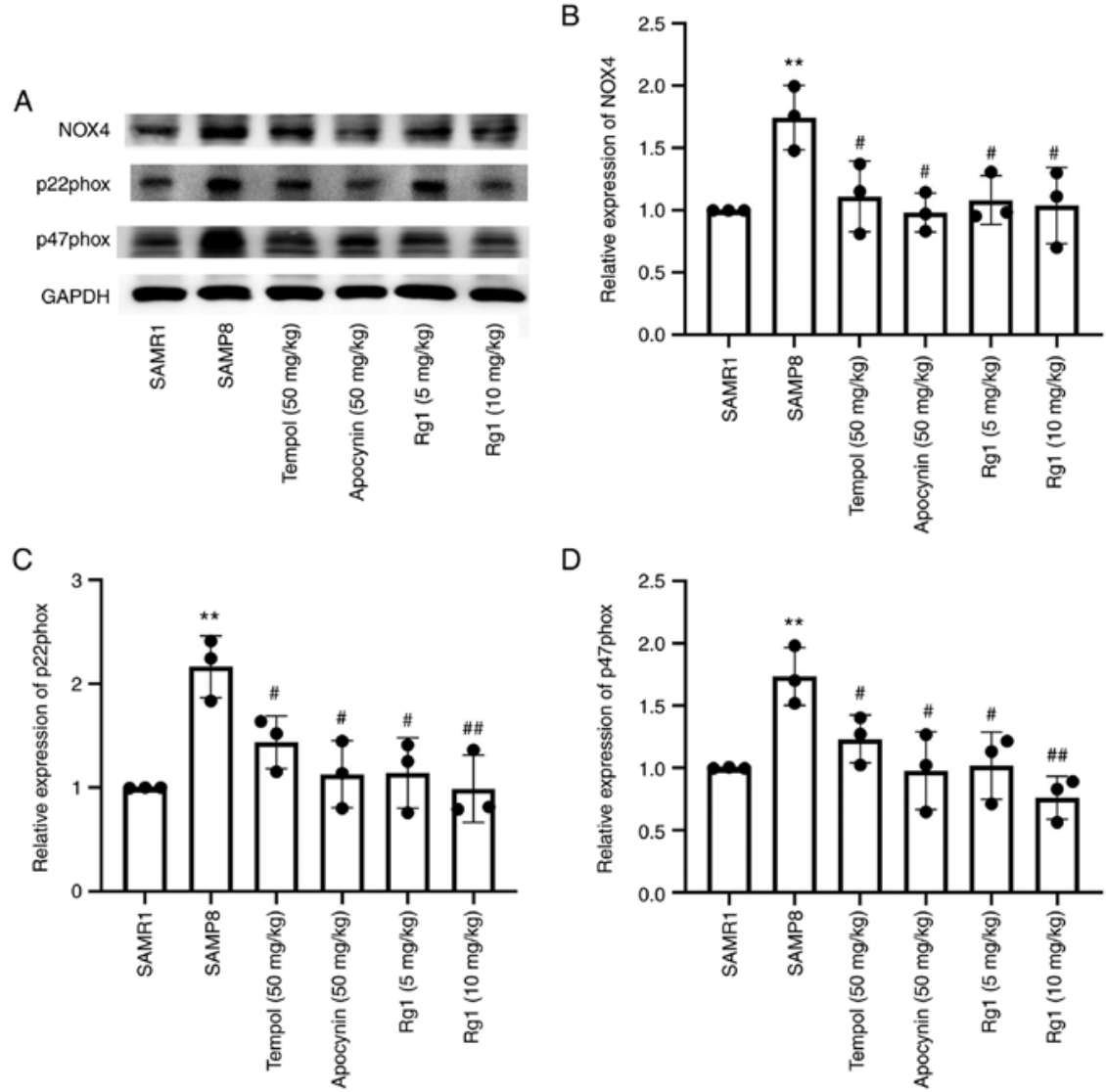

Figure 5. Effect of Rg1 treatment on NOX4 expression in the liver of SAMP8 mice. (A) Western blotting was used to determine the expression levels of NOX4, p22phox and p47phox in the liver of SAMP8 mice. Semi-quantitative analysis of the relative expression of (B) NOX4, (C) p22phox and (D) p47phox. Protein expression levels were normalized to GAPDH. Data are presented as the mean $\pm \mathrm{SD} ; \mathrm{n}=3 .{ }^{* *} \mathrm{P}<0.01$ vs. SAMR1; ${ }^{\#} \mathrm{P}<0.05$, ${ }^{\# \#} \mathrm{P}<0.01$ vs. SAMP8. Rg1, ginsenoside Rg1; SAMP8, senescence-accelerated mouse prone 8; SAMR1, senescence-accelerated resistant mouse 1; NOX4, NADPH oxidase 4.

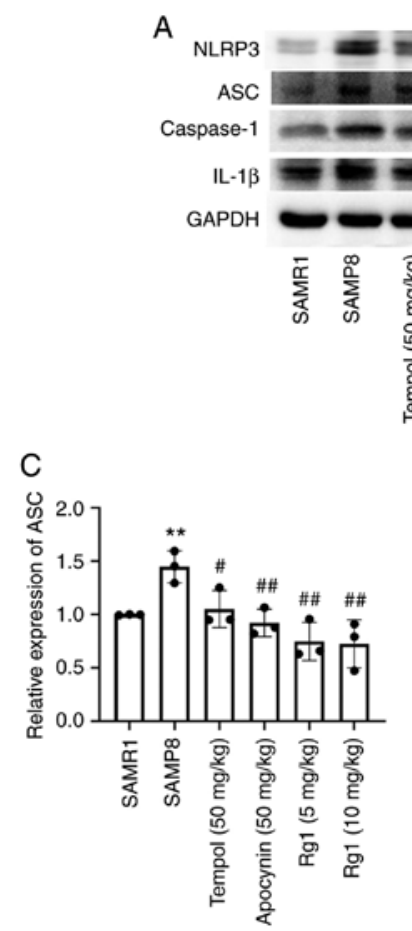

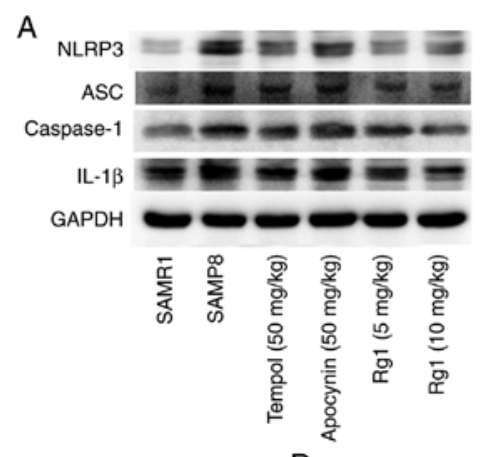

$\mathrm{D}$

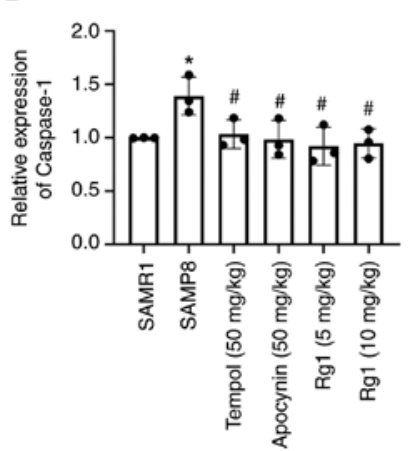

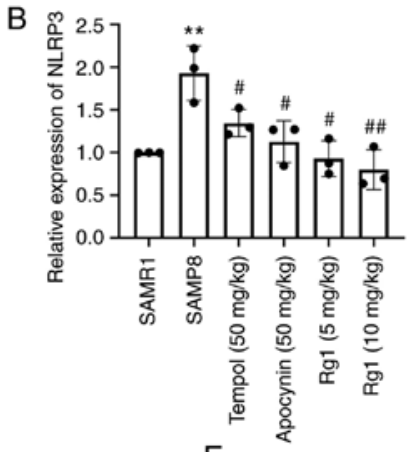

$\mathrm{E}$

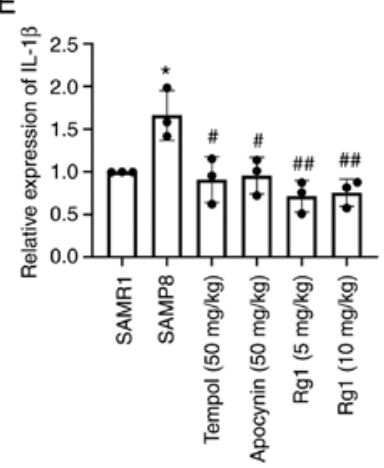

Figure 6. Effects of Rg1 treatment on the expression levels of NLRP3, ASC, caspase-1 and IL-1 $\beta$ in the liver of SAMP8 mice. (A) Western blotting was used to analyze the expression levels of NLRP3, ASC, caspase-1 and IL-1 $\beta$ in the liver of SAMP8 mice. Semi-quantitative analysis of the relative expression of (B) NLRP3, (C) ASC, (D) caspase-1 and (E) IL-1 1 . Protein expression levels were normalized to GAPDH. Data are presented as the mean \pm SD; $n=3$. "P<0.05, ${ }^{* *} \mathrm{P}<0.01$ vs. SAMR1; " $\mathrm{P}<0.05,{ }^{\# \#} \mathrm{P}<0.01$ vs. SAMP8. Rg1, ginsenoside Rg1; SAMP8, senescence-accelerated mouse prone 8; SAMR1, senescence-accelerated resistant mouse 1; NLRP3, NLR family pyrin domain containing 3; ASC, apoptosis-associated speck-like protein containing a C-terminal caspase recruitment domain. 


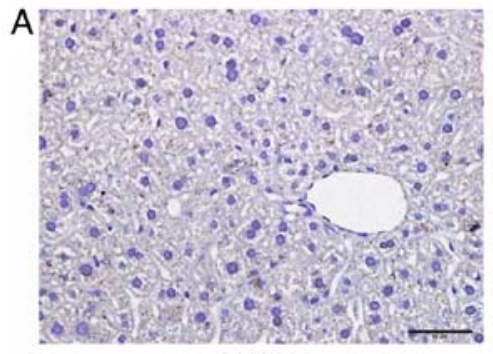

SAMR1

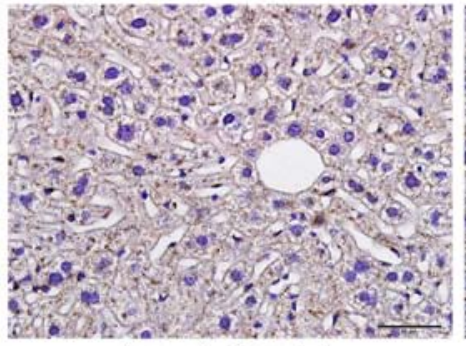

Apocynin $(50 \mathrm{mg} / \mathrm{kg})$

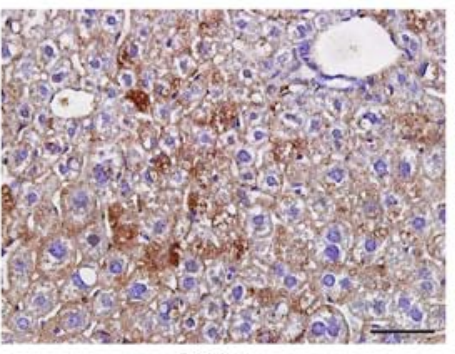

SAMP8

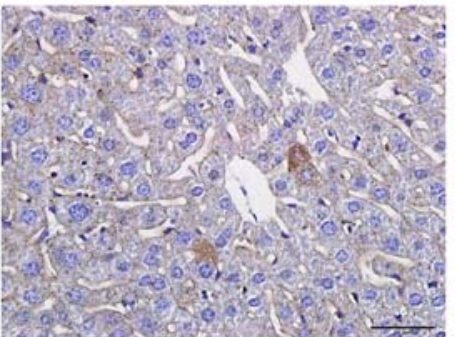

$\mathrm{Rg} 1(5 \mathrm{mg} / \mathrm{kg})$

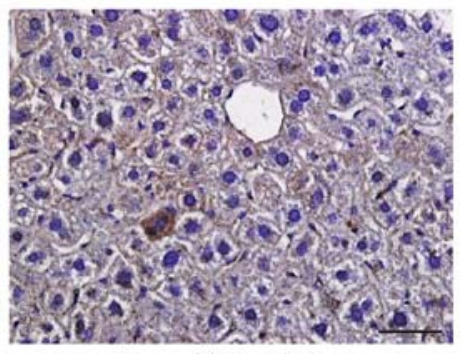

Tempol (50 mg/kg)

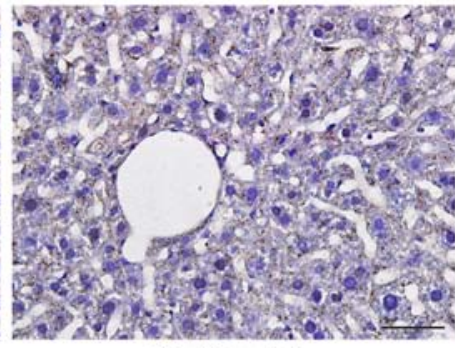

$\operatorname{Rg} 1(10 \mathrm{mg} / \mathrm{kg})$

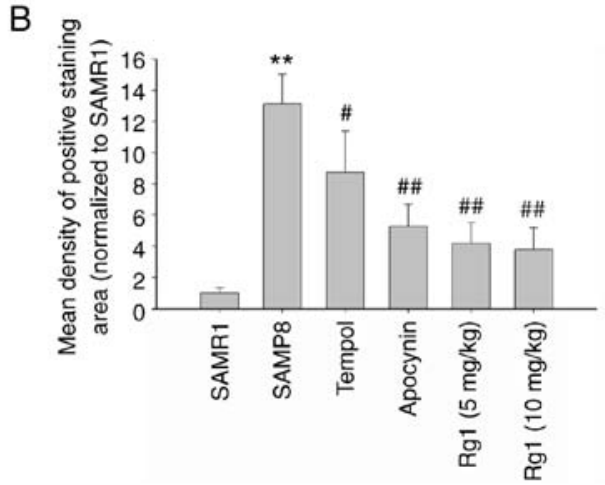

Figure 7. Effects of Rg1 treatment on the expression levels of NLRP3 in the liver of SAMP8 mice. (A) Expression of NLRP3 in the liver (Scale bar, $50 \mu$ m; Magnification, $\mathrm{x} 400$ ). (B) Mean density of the NLRP3-positive staining area in the liver. Data are presented as the mean \pm SD; $\mathrm{n}=4$. ${ }^{* *} \mathrm{P}<0.01 \mathrm{vs}$. SAMR1; ${ }^{\#} \mathrm{P}<0.05,{ }^{\#} \mathrm{P}<0.01$ vs. SAMP8. Rg1, ginsenoside Rg1; SAMP8, senescence-accelerated mouse prone 8; SAMR1, senescence-accelerated resistant mouse 1; NLRP3, NLR family pyrin domain containing 3.

and $\operatorname{Rg} 1$ (5 and $10 \mathrm{mg} / \mathrm{kg}$ ) treatment significantly downregulated the expression levels of NLRP3 (Fig. 7A and B). These results suggested that NLRP3 inflammasome activation may be closely related to liver fibrosis during aging and $\operatorname{Rg} 1$ may improve liver fibrosis by inhibiting the activation of the NLRP3 inflammasome.

To further investigate whether the inflammatory response was involved in liver fibrosis during aging, the expression levels of $\mathrm{NF}-\kappa \mathrm{B}$ and $\mathrm{p}-\mathrm{NF}-\kappa \mathrm{B}$ were measured in liver tissues using western blotting. The results revealed that there were no significant differences in the expression levels of $\mathrm{NF}-\kappa \mathrm{B}$ among the groups (Fig. 8A and B). However, the expression levels of $\mathrm{p}-\mathrm{NF}-\kappa \mathrm{B}$ were significantly increased in the SAMP8 group compared with the SAMR1 group (Fig. 8A and C), and tempol, apocynin and Rg1 (5 and $10 \mathrm{mg} / \mathrm{kg}$ ) treatment significantly downregulated the expression levels of $\mathrm{p}-\mathrm{NF}-\kappa \mathrm{B} / \mathrm{NF}-\kappa \mathrm{B}$ compared with the SAMP8 group (Fig. 8A and C). The results suggested that Rg1 may inhibit inflammation in the liver during aging by decreasing the phosphorylation of $\mathrm{NF}-\kappa \mathrm{B}$.

\section{Discussion}

Aging can promote the dysfunction of numerous organs, such as the liver, kidney and brain (43). Aging has been demonstrated to increase the susceptibility to hepatic inflammation or fibrosis (5). Liver fibrosis destroys the structure of the liver, leading to loss of liver cells and disruption of liver function, ultimately resulting in liver failure (44). However, the mechanisms of aging-induced liver injury and fibrosis are still unclear and there are no effective drugs for treating aging-related liver fibrosis. Therefore, it is important to explore the mechanism of liver aging and find appropriate medicines to prevent liver injury and fibrosis at an early age to reduce the incidence of age-related liver diseases.

$\mathrm{Rg} 1$, one of the main active components of ginseng, has been previously investigated for its anti-inflammatory and antioxidant properties and has been found to exert a protective effect on the liver (45). Previous studies have shown that $\mathrm{Rg} 1$ could inhibit the transformation of hepatic stellate cells into myofibroblasts and inhibit liver fibrosis in $\mathrm{CCl}_{4}$-induced mice $(45,46)$. Our previous study indicated that Rg1 (5 and $10 \mathrm{mg} / \mathrm{kg}$ ) treatment significantly improved aging-induced renal injury and fibrosis in SAMP8 mice (35). The present study was designed to study the effect and mechanism of $\mathrm{Rg} 1$ (5 and $10 \mathrm{mg} / \mathrm{kg}$ ) treatment on aging-related liver injury and fibrosis in SAMP8 mice during aging. The results indicated that $\mathrm{Rg} 1$ (5 and $10 \mathrm{mg} / \mathrm{kg}$ ) treatment could protect against 


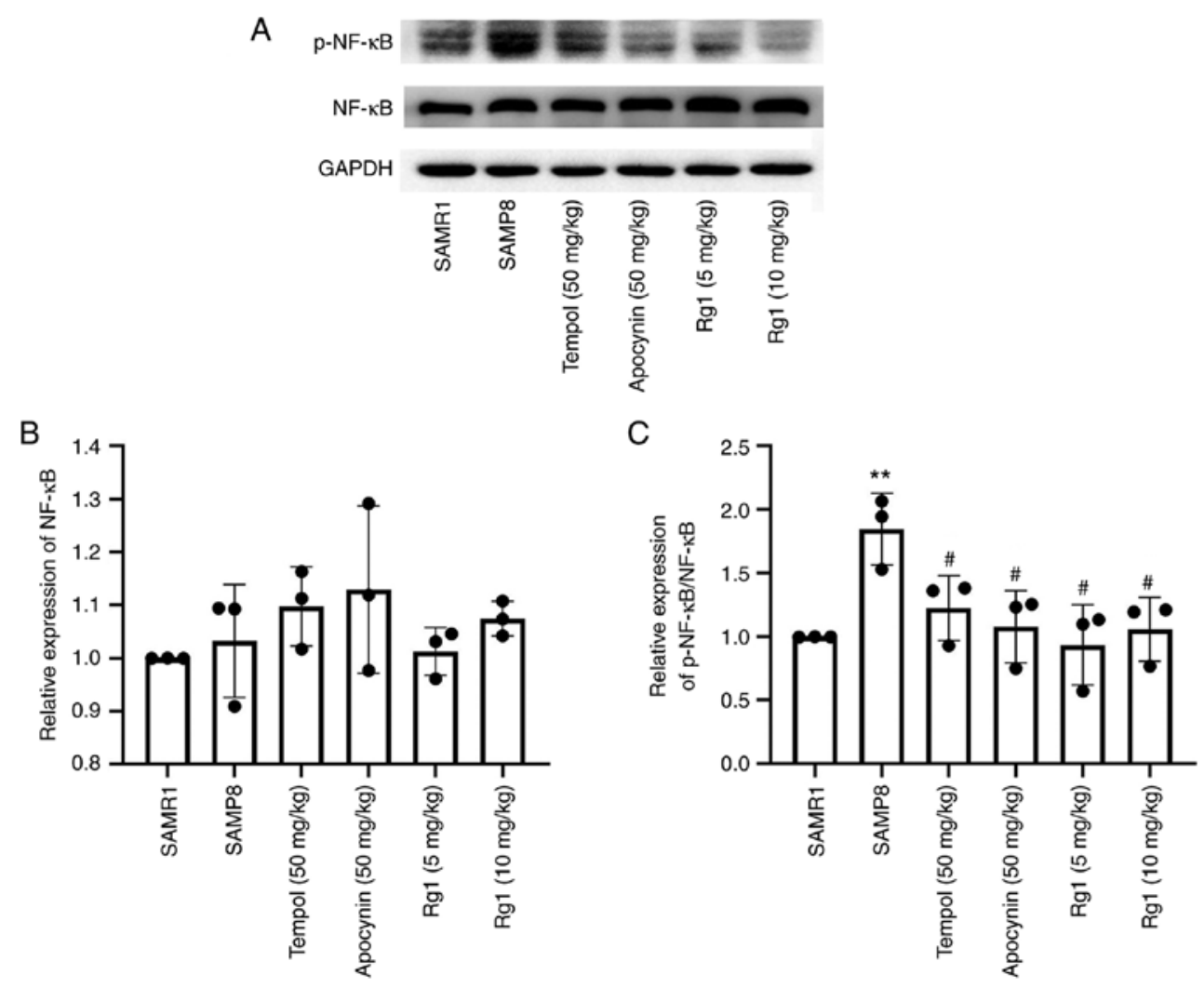

Figure 8. Effects of Rg1 treatment on the expression levels of p-NF- $\mathrm{kB}$ in the liver of SAMP8 mice. (A) Western blotting was used to analyze the expression

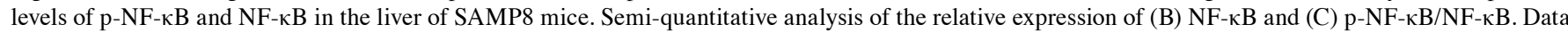
are presented as the mean $\pm \mathrm{SD} ; \mathrm{n}=3 .{ }^{* *} \mathrm{P}<0.01$ vs. SAMR1; ${ }^{*} \mathrm{P}<0.05$ vs. SAMP8. $\mathrm{Rg} 1$, ginsenoside $\mathrm{Rg} 1$; SAMP8, senescence-accelerated mouse prone 8; SAMR1, senescence-accelerated resistant mouse $1 ; \mathrm{p}$-, phosphorylated.

aging-induced liver injury and fibrosis, especially the Rg1 $(10 \mathrm{mg} / \mathrm{kg})$ group. These results also discovered that the arrangement of hepatocytes was abnormal and disordered and most of the cells appeared to have vacuole-like degeneration in the SAMP8 group, while $\operatorname{Rg} 1$ treatment showed a significant improvement in liver histopathology. In addition, the results discovered that NOX4/NLRP3 inflammasome signaling, which is closely associated with age-related liver injury and liver fibrosis (20), was significantly inhibited by $\mathrm{Rg} 1$ ( 5 and $10 \mathrm{mg} / \mathrm{kg}$ ) treatment, especially in the $\operatorname{Rg} 1(10 \mathrm{mg} / \mathrm{kg}$ ) group. These results suggested that $\operatorname{Rg} 1$ treatment may be effective in preventing aged-related injury and fibrosis in a dose-dependent manner, possibly by inhibiting NOX4 and the NLRP3 inflammasome.

Previous studies have shown that aging is an important factor that is closely associated with the generation and progression of liver fibrosis $(5,47)$; however, there is currently a lack of effective therapeutic options. Ginseng is one of the most widely used natural products, due to its wide range of pharmacological effects and biological activities that can delay aging (48). The active ingredient, $\mathrm{Rg} 1$, has been reported to exert protective effects on TGF- $\beta$-induced HSC-T6 cells and $\mathrm{CCl}_{4}$-induced liver fibrosis in male Kunming mice (31). In the present study, the results indicated that the liver tissues were significantly damaged and showed signs of fibrosis in 8-month-old SAMP8 mice, such as disordered cell arrangement, vacuolar degeneration and excess extracellular collagen IV deposition, sharing a number of similarities with the findings of Dumeus et al (49).
Notably, $\operatorname{Rg} 1$ treatment for 9 weeks was found to significantly attenuate liver injury and extracellular matrix accumulation in SAMP8 mice. It was previously shown that TGF- $\beta 1$ promoted liver fibrosis through Smad2 phosphorylation (p-Smad2) and collagen synthesis, and depleting TGF- $\beta 1$ could reduce liver fibrosis (50). In the present study, the results demonstrated that $\operatorname{Rg} 1$ treatment significantly decreased the expression of TGF- $\beta 1$ in the liver of SAMP8 mice. Tempol is an active oxygen scavenger, which has been reported to reduce the production of ROS in $\mathrm{H}_{2} \mathrm{O}_{2}$-treated hippocampal neurons due to its ROS scavenging capacity (51). Apocynin is often used as an inhibitor of NADPH oxidase, and it has been shown to possess a clear and obvious antioxidant effect on a variety of central nervous system diseases, including Parkinson's disease and Alzheimer's disease (52-54). The current study also demonstrated that tempol and apocynin exerted similar protective effects on aging-induced liver injury. These data suggested that $\operatorname{Rg} 1$ treatment may significantly protect against aging-induced liver injury and fibrosis in elderly mice.

It is well known that excessive ROS-induced oxidative stress plays a critical role in the pathogenesis of aging, which is also closely related to age-related diseases, including liver injury and fibrosis $(7,55)$. The imbalance between the production and clearance of ROS determines the degree of oxidative stress (56). Multiple enzymes contribute to ROS generation and oxidative stress in various tissues or cells. NOX has been reported to be a major source of ROS in numerous types of organ, such as kidney and liver, and previous research has 
shown that NOX4 was a major ROS-producing enzyme in the liver (57). It has been reported that NOX4 plays crucial roles in liver tissues under physiological conditions by mediating ROS generation (14). The accumulation of NOX4-derived ROS is also an important regulator in promoting liver fibrosis (58). A previous study showed that $\operatorname{Rg} 1$ could significantly improve the survival rates of HepG2 and 293 cells in acetaminophen-induced liver injury by reducing the excessive ROS production (59). Furthermore, evidence has shown that Rg1 reduces ROS production by inhibiting NOX4 expression in obese zebrafish induced by a high-fat diet (60). Our previous study found that $\operatorname{Rg} 1$ treatment could significantly downregulate the expression of NOX4 and p47phox in the kidney of aging SAMP8 mice (35). Similarly, the findings of the present study found that the ROS production and the expression levels of NOX4, p47phox and p22phox were significantly increased in the liver of elderly SAMP8 mice compared with the control group, suggesting that NOX4-mediated ROS accumulation is closely involved in senescence-related liver fibrosis. Fernández-Garcia et al (61) also demonstrated a significant increase in ROS levels in the livers of SAMP8 mice. In addition, the present results also indicated that tempol, apocynin and $\operatorname{Rg} 1$ administration markedly reduced ROS production and the expression levels of NOX4, p22phox and p47phox in the livers of SAMP8 mice. These results suggested that Rg1 may improve aging-induced liver injury by reducing NOX4-mediated ROS accumulation.

Increasing evidence has shown that oxidative stress may also be closely associated with the levels of inflammation, which also plays a crucial role in aging-related diseases $(62,63)$. A previous study demonstrated that the accumulation of senescent cells contributed to the development of fibrosis by secreting proinflammatory cytokines and profibrotic mediators (64). ROS, as signaling molecules, have been discovered to play important roles in numerous processes of inflammation-related diseases. For example, deoxynivalenol induced the inflammation of IPEC-J2 cells by promoting ROS production $(65,66)$. There has been a consensus that inflammasome complexes play central roles in promoting inflammation in a number of tissues, such as in the colon and brain (67-69). Excessive ROS production is an important process for the activation of inflammasome complexes (70-72). The NLRP3 inflammasome has been reported to be extensively expressed in the liver $(20,73)$. Previous studies have reported that the NLRP3 inflammasome was activated in the progression of alcoholic liver disease (ALD), and liver inflammation and steatosis were significantly improved in ALD mice with knocked out NLRP3 or caspase-1 expression (74,75). Activated NLRP3 can bind to ASC, causing procaspase-1 to be cleaved into mature caspase-1. Caspase-1 further catalyzes the cleavage of pro-IL-1 $\beta$ and pro-IL-18 into their mature forms, IL-1 $\beta$ and IL-18 (19). A previous study reported that NLRP3 activation aggravated inflammation in liver disease and subsequent fibrosis (76). In addition, another study showed that $\mathrm{Rg} 1$ treatment improved $\mathrm{CCl}_{4}$-induced acute liver injury by suppressing the $\mathrm{NF}-\kappa \mathrm{B} / \mathrm{NLRP} 3$ inflammasome signaling pathway (77). In the present study, the results suggested that the expression levels of IL-1 $\beta$, ASC, caspase-1 and NLRP3 were upregulated in the liver tissues of SAMP8 mice. These results are consistent with previous studies (35), and provide further support for the role of the NLRP3 inflammasome in the occurrence of aging-related liver injury in SAMP8 mice (78). The improvement of inflammation and inhibition of NLRP3 inflammasome activation have been observed to exert protective effects on target organs (76). Similarly, the present study found that treatment with tempol, apocynin and Rg1 significantly downregulated the expression levels of IL-1 $\beta$, ASC, caspase-1 and NLRP3 in the liver tissues of SAMP8 mice. It is well known that the $\mathrm{NF}-\kappa \mathrm{B}$ transcription factor family is a central regulator of the inflammatory process (79). Phosphorylation of $N F-\kappa B$ at serine 536 is thought to be required for $\mathrm{NF}-\kappa \mathrm{B}$ activation and nuclear translocation (80). It has been reported that selective inhibition of $\mathrm{NF}-\kappa \mathrm{B}$ activity can suppress $\mathrm{CCl}_{4}$-induced liver fibrosis (81). In this study, the results revealed that the expression of $\mathrm{p}-\mathrm{NF}-\kappa \mathrm{B}$, which promotes the formation of the NLRP3 inflammasome, was significantly upregulated in the liver tissues of aging mice and was significantly decreased after Rg1 treatment for 9 weeks in SAMP8 mice. Altogether, these findings indicated that the NLRP3 inflammasome may be an important target and is closely involved in aging-induced liver injury. Furthermore, inhibition of the NLRP3 inflammasome may be an important underlying mechanism of $\mathrm{Rg} 1$ in preventing aging-related liver injury and fibrosis.

In conclusion, the findings of the present study suggested that Rg1 treatment may ameliorate aging-associated liver injury and fibrosis in SAMP8 mice. Rg1 treatment significantly decreased the levels of ROS accumulation and NOX4 expression. In addition, Rg1 treatment significantly downregulated the expression of the NLRP3 inflammasome in the liver of SAMP8 mice. These results suggest that Rg1 may delay liver aging and reduce age-related liver fibrosis by reducing NOX4-mediated ROS-induced oxidative stress and inhibiting the activation of the NLRP3 inflammasome. Thus, $\mathrm{Rg} 1$ may act as a potential treatment for the prevention of liver fibrosis during aging.

However, the current study has several limitations. For example, it only provided animal experimental results demonstrating that $\mathrm{Rg} 1$ ameliorated aging-related liver fibrosis due to the inhibition of NOX4 and NLRP3 inflammasome activation in SAMP8 mice. In addition, the biochemical indicators and serological indicators that represent liver function, inflammation and oxidative stress levels were not measured. Future research will aim to further study the effect of Rg1 treatment on aging-induced liver function, inflammation and oxidative stress-related indicators in the serum, such as aspartate aminotransferase, alanine transaminase, IL-1 $\beta$ and superoxide dismutase. Furthermore, NOX4 inhibitors or NOX4 knockout experiments will be performed to further investigate the exact underlying protective mechanism of Rg1 against liver injury in vitro and in vivo.

\section{Acknowledgements}

We would like to thank Mrs. Zhirui Fang (Department of Pharmacology, Anhui Medical University) for helping with immunohistochemistry staining and Mr. Dake Huang (Synthetic Laboratory of Basic Medicine College, Anhui Medical University) for helping with frozen section. 


\section{Funding}

The present study was supported by grants from the National Natural Science Foundation of China (grant no. 81970630) and the Major Science and Technology Projects in Anhui Province (grant no. 201903a07020025).

\section{Availability of data and materials}

The datasets used and/or analyzed during the current study are available from the corresponding author on reasonable request.

\section{Authors' contributions}

WZL and WPL conceived and designed the study; YL, DZ and LL performed the experiments and statistical analysis and wrote the manuscript; YH and XD confirmed the authenticity of all the raw data. YH, XD, LY and XL helped to perform the experiments and wrote part of the manuscript. All authors read and approved the final manuscript.

\section{Ethics approval and consent to participate}

The experimental procedures were approved by the Animal Ethics Committee of Anhui Medical University (approval no. LLSC20160183; Hefei, China) and performed in accordance with the Guidelines for the Care and Use of Laboratory Animals.

\section{Patient consent for publication}

Not applicable.

\section{Competing interests}

The authors declare that they have no competing interests.

\section{References}

1. Stahl EC, Haschak MJ, Popovic B and Brown BN: Macrophages in the aging liver and age-related liver disease. Front Immunol 9: 2795,2018

2. Tominaga $\mathrm{K}$ and Suzuki HI: TGF- $\beta$ signaling in cellular senescence and aging-related pathology. Int J Mol Sci 20: 5002, 2019.

3. Iwaisako K, Brenner DA and Kisseleva T: What's new in liver fibrosis? The origin of myofibroblasts in liver fibrosis. J Gastroenterol Hepatol 27 (Suppl 2): S65-S68, 2012.

4. Aydin MM and Akçalı KC: Liver fibrosis. Turk J Gastroenterol 29: $14-21,2018$.

5. Kim IH, Xu J, Liu X, Koyama Y, Ma HY, Diggle K, You YH, Schilling JM, Jeste D, Sharma K, et al: Aging increases the susceptibility of hepatic inflammation, liver fibrosis and aging in response to high-fat diet in mice. Age (Dordr) 38: 291-302, 2016.

6. Stefanatos R and Sanz A: The role of mitochondrial ROS in the aging brain. FEBS Lett 592: 743-758, 2018.

7. Davalli P, Mitic T, Caporali A, Lauriola A and D'Arca D: ROS, cell senescence, and novel molecular mechanisms in aging and age-related diseases. Oxid Med Cell Longev 2016: 3565127, 2016.

8. Kudryavtseva AV, Krasnov GS, Dmitriev AA, Alekseev BY, Kardymon OL, Sadritdinova AF, Fedorova MS, Pokrovsky AV, Melnikova NV, Kaprin AD, et al: Mitochondrial dysfunction and oxidative stress in aging and cancer. Oncotarget 7: 44879-44905, 2016.

9. Luangmonkong T, Suriguga S, Mutsaers HAM, Groothuis GMM, Olinga $\mathrm{P}$ and Boersema $\mathrm{M}$ : Targeting oxidative stress for the treatment of liver fibrosis. Rev Physiol Biochem Pharmacol 175: 71-102, 2018
10. Tao Y, Qiu T, Yao X, Jiang L, Wang N, Jiang J, Jia X, Wei S, Zhang J, Zhu Y, et al: IRE1a/NOX4 signaling pathway mediates ROS-dependent activation of hepatic stellate cells in $\mathrm{NaAsO}_{2}$-induced liver fibrosis. J Cell Physiol 236: 1469-1480, 2021.

11. Valko M, Leibfritz D, Moncol J, Cronin MT, Mazur M and Telser J: Free radicals and antioxidants in normal physiological functions and human disease. Int J Biochem Cell Biol 39: 44-84, 2007.

12. Ushio-Fukai M: VEGF signaling through NADPH oxidase-derived ROS. Antioxid Redox Signal 9: 731-739, 2007.

13. Ghosh R, Siddharth M, Singh N, Kare PK, Banerjee BD, Wadhwa N and Tripathi AK: Organochlorine pesticide-mediated induction of NADPH oxidase and nitric-oxide synthase in endothelial cell. J Clin Diagn Res 11: BC09-BC12, 2017.

14. Cheng Q, Li C, Yang CF, Zhong YJ, Wu D, Shi L, Chen L, Li YW and Li L: Methyl ferulic acid attenuates liver fibrosis and hepatic stellate cell activation through the TGF- $\beta 1 /$ Smad and NOX4/ROS pathways. Chem Biol Interact 299: 131-139, 2019.

15. Chen Y, Zhao C, Liu X, Wu G, Zhong J, Zhao T, Li J, Lin Y, Zhou Y and Wei Y: Plumbagin ameliorates liver fibrosis via a ROS-mediated NF- $\kappa \mathrm{B}$ signaling pathway in vitro and in vivo. Biomed Pharmacother 116: 108923, 2019.

16. Fougère B, Boulanger E, Nourhashémi F, Guyonnet $S$ and Cesari M: Chronic inflammation: Accelerator of biological aging. J Gerontol A Biol Sci Med Sci 72: 1218-1225, 2017.

17. Soysal P, Arik F, Smith L, Jackson SE and Isik AT: Inflammation, frailty and cardiovascular disease. Adv Exp Med Biol 1216: 55-64, 2020.

18. Neves $\mathbf{J}$ and Sousa-Victor P: Regulation of inflammation as an anti-aging intervention. FEBS J 287: 43-52, 2020.

19. Mangan MSJ, Olhava EJ, Roush WR, Seidel HM, Glick GD and Latz E: Targeting the NLRP3 inflammasome in inflammatory diseases. Nat Rev Drug Discov 17: 588-606, 2018.

20. Gallego P, Castejón-Vega B, Del Campo JA and Cordero MD: The absence of NLRP3-inflammasome modulates hepatic fibrosis progression, lipid metabolism, and inflammation in $\mathrm{KO}$ NLRP3 mice during aging. Cells 9: 2148, 2020.

21. Sun L, Ma W, Gao W, Xing Y, Chen L, Xia Z, Zhang Z and Dai Z: Propofol directly induces caspase-1-dependent macrophage pyroptosis through the NLRP3-ASC inflammasome. Cell Death Dis 10: 542, 2019.

22. Stancu IC, Cremers N, Vanrusselt H, Couturier J, Vanoosthuyse A, Kessels S, Lodder C, Brône B, Huaux F, Octave JN, et al: Aggregated tau activates NLRP3-ASC inflammasome exacerbating exogenously seeded and non-exogenously seeded tau pathology in vivo. Acta Neuropathol 137: 599-617, 2019.

23. Yin Y, Pastrana JL, Li X, Huang X, Mallilankaraman K, Choi ET, Madesh M, Wang H and Yang XF: Inflammasomes: Sensors of metabolic stresses for vascular inflammation. Front Biosci (Landmark Ed) 18: 638-649, 2013.

24. Guo H, Callaway JB and Ting JP: Inflammasomes: Mechanism of action, role in disease, and therapeutics. Nat Med 21: 677-687, 2015.

25. Malik A and Kanneganti TD: Inflammasome activation and assembly at a glance. J Cell Sci 130: 3955-3963, 2017.

26. Zhang M, Zhu X, Tong H, Lou A, Li Y, Li Y, Su L and Li X: AVE 0991 attenuates pyroptosis and liver damage after heatstroke by inhibiting the ROS-NLRP3 inflammatory signalling pathway. Biomed Res Int 2019: 1806234, 2019.

27. Baltanás A, Solesio ME, Zalba G, Galindo MF, Fortuño A and Jordán J: The senescence-accelerated mouse prone-8 (SAM-P8) oxidative stress is associated with upregulation of renal NADPH oxidase system. J Physiol Biochem 69: 927-935, 2013.

28. Maroni L, Pinto C, Giordano DM, Saccomanno S, Banales JM, Spallacci D, Albertini MC, Orlando F, Provinciali M, Milkiewicz M, et al: Aging-related expression of twinfilin-1 regulates cholangiocyte biological response to injury. Hepatology 70 : 883-898, 2019.

29. Ye X, Meeker HC, Kozlowski PB, Wegiel J, Wang KC, Imaki H and Carp RI: Pathological changes in the liver of a senescence accelerated mouse strain (SAMP8): A mouse model for the study of liver diseases. Histol Histopathol 19: 1141-1151, 2004.

30. Xiong X, Ren Y, Cui Y, Li R, Wang C and Zhang Y: Obeticholic acid protects mice against lipopolysaccharide-induced liver injury and inflammation. Biomed Pharmacother 96: 1292-1298, 2017.

31. Wei X, Chen Y and Huang W: Ginsenoside Rg1 ameliorates liver fibrosis via suppressing epithelial to mesenchymal transition and reactive oxygen species production in vitro and in vivo. Biofactors 44: 327-335, 2018. 
32. Kim DH: Chemical diversity of Panax ginseng, Panax quinquifolium, and Panax notoginseng. J Ginseng Res 36: 1-15, 2012.

33. Xu TZ, Shen XY, Sun LL, Chen YL, Zhang BQ, Huang DK and $\mathrm{Li}$ WZ: Ginsenoside $\mathrm{Rg} 1$ protects against $\mathrm{H}_{2} \mathrm{O}_{2}$-induced neuronal damage due to inhibition of the NLRP1 inflammasome signalling pathway in hippocampal neurons in vitro. Int J Mol Med 43: 717-726, 2019.

34. Schmucker DL: Age-related changes in liver structure and function: Implications for disease ? Exp Gerontol 40: 650-659, 2005.

35. Shen X, Dong X, Han Y, Li Y, Ding S, Zhang H, Sun Z, Yin Y, Li W and Li W: Ginsenoside Rg1 ameliorates glomerular fibrosis during kidney aging by inhibiting NOX4 and NLRP3 inflammasome activation in SAMP8 mice. Int Immunopharmacol 82: 106339, 2020.

36. Chen Y, Ding S, Zhang H, Sun Z, Shen X, Sun L, Yin Y, Qun S and $\mathrm{Li} \mathrm{W}$ : Protective effects of ginsenoside Rg1 on neuronal senescence due to inhibition of NOX2 and NLRP1 inflammasome activation in SAMP8 mice. J Funct Foods 65: 103713, 2020.

37. Jones-Bolin S: Guidelines for the care and use of laboratory animals in biomedical research. Curr Protoc Pharmacol 4: 4B 2012.

38. Wick MR: The hematoxylin and eosin stain in anatomic pathology-an often-neglected focus of quality assurance in the laboratory. Semin Diagn Pathol 36: 303-311, 2019.

39. Lefkowitch JH: Special stains in diagnostic liver pathology. Semin Diagn Pathol 23: 190-198, 2006.

40. Iezzoni JC: Diagnostic histochemistry in hepatic pathology. Semin Diagn Pathol 35: 381-389, 2018.

41. Yu H, Zhen J, Yang Y, Gu J, Wu S and Liu Q: Ginsenoside Rg1 ameliorates diabetic cardiomyopathy by inhibiting endoplasmic reticulum stress-induced apoptosis in a streptozotocin-induced diabetes rat model. J Cell Mol Med 20: 623-631, 2016.

42. Liu Q, Zhang FG, Zhang WS, Pan A, Yang YL, Liu JF, Li P Liu BL and Qi LW: Ginsenoside Rg1 inhibits glucagon-induced hepatic gluconeogenesis through Akt-FoxO1 interaction. Theranostics 7: 4001-4012, 2017.

43. Childs BG, Durik M, Baker DJ and van Deursen JM: Cellular senescence in aging and age-related disease: From mechanisms to therapy. Nat Med 21: 1424-1435, 2015.

44. Kisseleva T and Brenner DA: Mechanisms of fibrogenesis. Exp Biol Med (Maywood) 233: 109-122, 2008.

45. Mo C, Xie S, Zeng T, Lai Y, Huang S, Zhou C, Yan W, Huang S, Gao L and Lv Z: Ginsenoside-Rg1 acts as an IDO1 inhibitor, protects against liver fibrosis via alleviating IDO1-mediated the inhibition of DCs maturation. Phytomedicine 84: 153524, 2021.

46. Li JP, Gao Y, Chu SF, Zhang Z, Xia CY, Mou Z, Song XY, He WB, Guo XF and Chen NH: Nrf2 pathway activation contributes to anti-fibrosis effects of ginsenoside $\operatorname{Rg} 1$ in a rat model of alcohol- and CCl4-induced hepatic fibrosis. Acta Pharmacol Sin 35: 1031-1044, 2014.

47. Jin CJ, Baumann A, Brandt A, Engstler AJ, Nier A, Hege M, Schmeer C, Kehm R, Höhn A, Grune T, et al: Aging-related liver degeneration is associated with increased bacterial endotoxin and lipopolysaccharide binding protein levels. Am J Physiol Gastrointest Liver Physiol 318: G736-G747, 2020.

48. Qin Q, Lin N, Huang H, Zhang X, Cao X, Wang Y and Li P: Ginsenoside $\operatorname{Rg} 1$ ameliorates cardiac oxidative stress and inflammation in streptozotocin-induced diabetic rats. Diabetes Metab Syndr Obes 12: 1091-1103, 2019.

49. Dumeus S, Shibu MA, Lin WT, Wang MF, Lai CH, Shen CY, Lin YM, Viswanadha VP, Kuo WW and Huang CY: Bioactive peptide improves diet-induced hepatic fat deposition and hepatocyte proinflammatory response in SAMP8 ageing mice. Cell Physiol Biochem 48: 1942-1952, 2018.

50. Xu F, Liu C, Zhou D and Zhang L: TGF- $\beta /$ SMAD pathway and its regulation in hepatic fibrosis. J Histochem Cytochem 64: 157-167, 2016

51. Wang Y, Liu Q, Xu Y, Zhang Y, Lv Y, Tan Y, Jiang N, Cao G, Ma X, Wang J, et al: Ginsenoside Rg1 protects against oxidative stress-induced neuronal apoptosis through myosin IIA-actin related cytoskeletal reorganization. Int J Biol Sci 12: $1341-1356,2016$

52. Hou L, Sun F, Huang R, Sun W, Zhang D and Wang Q Inhibition of NADPH oxidase by apocynin prevents learning and memory deficits in a mouse Parkinson's disease model. Redox Biol 22: 101134, 2019.

53. Nayernia Z, Jaquet V and Krause KH: New insights on NOX enzymes in the central nervous system. Antioxid Redox Signal 20: 2815-2837, 2014.
54. Langley M, Ghosh A, Charli A, Sarkar S, Ay M, Luo J, Zielonka J, Brenza T, Bennett B, Jin H, et al: Mito-apocynin prevents mitochondrial dysfunction, microglial activation, oxidative damage, and progressive neurodegeneration in MitoPark transgenic mice. Antioxid Redox Signal 27: 1048-1066, 2017.

55. Hsieh CC and Papaconstantinou J: Thioredoxin-ASK1 complex levels regulate ROS-mediated p38 MAPK pathway activity in livers of aged and long-lived Snell dwarf mice. FASEB J 20 259-268, 2006

56. Wojtovich AP and Foster TH: Optogenetic control of ROS production. Redox Biol 2: 368-376, 2014

57. Huang C, Gan D, Luo F, Wan S, Chen J, Wang A, Li B and Zhu X: Interaction mechanisms between the NOX4/ROS and RhoA/ROCK1 signaling pathways as new anti-fibrosis targets of ursolic acid in hepatic stellate cells. Front Pharmacol 10: 431, 2019.

58. Lan T, Kisseleva T and Brenner DA: Deficiency of NOX1 or NOX4 prevents liver inflammation and fibrosis in mice through inhibition of hepatic stellate cell activation. PLoS One 10: e0129743, 2015.

59. Gao Y, Chu SF, Zhang Z, Ai QD, Xia CY, Huang HY and Chen NH: Ginsenoside Rg1 prevents acetaminophen-induced oxidative stress and apoptosis via Nrf2/ARE signaling pathway. J Asian Nat Prod Res 21: 782-797, 2019.

60. Koh EJ, Kim KJ, Choi J, Jeon HJ, Seo MJ and Lee BY: Ginsenoside Rg1 suppresses early stage of adipocyte development via activation of C/EBP homologous protein-10 in 3T3-L1 and attenuates fat accumulation in high fat diet-induced obese zebrafish. J Ginseng Res 41: 23-30, 2017.

61. Fernández-Garcia C, Rancan L, Paredes SD, Montero C, de la Fuente M, Vara E and Tresguerres JAF: Xanthohumol exerts protective effects in liver alterations associated with aging. Eur J Nutr 58: 653-663, 2019.

62. Pinto C, Ninfole E, Benedetti A, Maroni L and Marzioni M: Aging-related molecular pathways in chronic cholestatic conditions. Front Med (Lausanne) 6: 332, 2020.

63. Stakos DA, Stamatelopoulos K, Bampatsias D, Sachse M, Zormpas E, Vlachogiannis NI, Tual-Chalot S and Stellos K: The Alzheimer's disease amyloid-beta hypothesis in cardiovascular aging and disease: JACC focus seminar. J Am Coll Cardiol 75: 952-967, 2020.

64. Sun X, Nkennor B, Mastikhina O, Soon K and Nunes SS: Endothelium-mediated contributions to fibrosis. Semin Cell Dev Biol 101: 78-86, 2020.

65. Zhu $\mathrm{H}$ and Li YR: Oxidative stress and redox signaling mechanisms of inflammatory bowel disease: Updated experimental and clinical evidence. Exp Biol Med (Maywood) 237: 474-480, 2012.

66. Kang R, Li R, Dai P, Li Z, Li Y and Li C: Deoxynivalenol induced apoptosis and inflammation of IPEC-J2 cells by promoting ROS production. Environ Pollut 251: 689-698, 2019.

67. Ralston JC, Lyons CL, Kennedy EB, Kirwan AM and Roche HM: Fatty acids and NLRP3 inflammasome-mediated inflammation in metabolic tissues. Annu Rev Nutr 37: 77-102, 2017.

68. Elinav E, Strowig T, Kau AL, Henao-Mejia J, Thaiss CA, Booth CJ, Peaper DR, Bertin J, Eisenbarth SC, Gordon JI and Flavell RA: NLRP6 inflammasome regulates colonic microbial ecology and risk for colitis. Cell 145: 745-757, 2011

69. Song AQ, Gao B, Fan JJ, Zhu YJ, Zhou J, Wang YL, $\mathrm{Xu}$ LZ and Wu WN: NLRP1 inflammasome contributes to chronic stress-induced depressive-like behaviors in mice. J Neuroinflammation 17: 178, 2020.

70. Yu X, Lan P, Hou X, Han Q, Lu N, Li T, Jiao C, Zhang J, Zhang C and Tian Z: HBV inhibits LPS-induced NLRP3 inflammasome activation and IL- $1 \beta$ production via suppressing the NF- $\kappa B$ pathway and ROS production. J Hepatol 66: 693-702, 2017.

71. Cheng YC, Chu LW, Chen JY, Hsieh SL, Chang YC, Dai ZK and Wu BN: Loganin attenuates high glucose-induced schwann cells pyroptosis by inhibiting ROS generation and NLRP3 inflammasome activation. Cells 9: 1948, 2020.

72. Sho $\mathrm{T}$ and $\mathrm{Xu} \mathrm{J}$ : Role and mechanism of ROS scavengers in alleviating NLRP3-mediated inflammation. Biotechnol Appl Biochem 66: 4-13,2019.

73. Wree A, McGeough MD, Inzaugarat ME, Eguchi A, Schuster S, Johnson CD, Peña CA, Geisler LJ, Papouchado BG, Hoffman HM and Feldstein AE: NLRP3 inflammasome driven liver injury and fibrosis: Roles of IL-17 and TNF in mice. Hepatology 67: 736-749, 2018.

74. Mridha AR, Wree A, Robertson AAB, Yeh MM, Johnson CD, Van Rooyen DM,Haczeyni F, Teoh NC,Savard C, Ioannou GN, et al: NLRP3 inflammasome blockade reduces liver inflammation and fibrosis in experimental NASH in mice. J Hepatol 66: 1037-1046, 2017. 
75. Cao Z, Fang Y, Lu Y, Tan D, Du C, Li Y, Ma Q, Yu J, Chen M, Zhou C, et al: Melatonin alleviates cadmium-induced liver injury by inhibiting the TXNIP-NLRP3 inflammasome. J Pineal Res 62: e12389, 2017.

76. Wree A, Eguchi A, McGeough MD, Pena CA, Johnson CD, Canbay A, Hoffman HM and Feldstein AE: NLRP3 inflammasome activation results in hepatocyte pyroptosis, liver inflammation, and fibrosis in mice. Hepatology 59: 898-910, 2014.

77. Zhao J, He B, Zhang S, Huang W and Li X: Ginsenoside Rg1 alleviates acute liver injury through the induction of autophagy and suppressing NF- $\kappa \mathrm{B} / \mathrm{NLRP} 3$ inflammasome signaling pathway. Int J Med Sci 18: 1382-1389, 2021.

78. Cuesta S, Kireev R, Forman K, García C, Escames G, Ariznavarreta C, Vara E and Tresguerres JA: Melatonin improves inflammation processes in liver of senescence-accelerated prone male mice (SAMP8). Exp Gerontol 45: 950-956, 2010.
79. Lawrence T: The nuclear factor NF-kappaB pathway in inflammation. Cold Spring Harb Perspect Biol 1: a001651, 2009.

80. Dolcet X, Llobet D, Pallares J and Matias-Guiu X: NF-kB in development and progression of human cancer. Virchows Arch 446: 475-482, 2005.

81. Zhou D, Huang W, Wei J, Zhang J, Liu Z, Ji R, Ge S, Xiao M, Fan Y and Lu C: RelB promotes liver fibrosis via inducing the release of injury-associated inflammatory cytokines. J Cell Mol Med 24: 6008-6014, 2020.

(i) (9) This work is licensed under a Creative Commons Attribution-NonCommercial-NoDerivatives 4.0 International (CC BY-NC-ND 4.0) License. 